\title{
GCU
}

Glasgow Caledonian

University

University for the Common Good

\section{SIF-based fracture criterion of rock-concrete interface and its application to the prediction of cracking paths in gravity dam}

Dong, Wei; Song, Shenzhen; Zhang, Binsheng; Yang, Dong

Published in:

Engineering Fracture Mechanics

DOI:

10.1016/j.engfracmech.2019.106686

Publication date:

2019

Document Version

Author accepted manuscript

Link to publication in ResearchOnline

Citation for published version (Harvard):

Dong, W, Song, S, Zhang, B \& Yang, D 2019, 'SIF-based fracture criterion of rock-concrete interface and its application to the prediction of cracking paths in gravity dam', Engineering Fracture Mechanics, vol. 221, 106686. https://doi.org/10.1016/j.engfracmech.2019.106686

\section{General rights}

Copyright and moral rights for the publications made accessible in the public portal are retained by the authors and/or other copyright owners and it is a condition of accessing publications that users recognise and abide by the legal requirements associated with these rights.

Take down policy

If you believe that this document breaches copyright please view our takedown policy at https://edshare.gcu.ac.uk/id/eprint/5179 for details of how to contact us. 


\title{
SIF-based fracture criterion of rock-concrete interface and its application to the prediction of cracking paths in gravity dam
}

\author{
Wei Dong ${ }^{1, *}$, Shenzhen Song ${ }^{2}$, Binsheng Zhang ${ }^{3}$, Dong Yang ${ }^{4}$
}

${ }^{1}$ Professor, State Key Laboratory of Coastal and Offshore Engineering, Dalian University of Technology, Dalian 116024, P. R. China. E-mail: dongwei@dlut.edu.cn

*Corresponding author

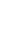

${ }^{2}$ Postgraduate student, State Key Laboratory of Coastal and Offshore Engineering, Dalian University of Technology, Dalian 116024, P. R. China. E-mail: songsz@mail.dlut.edu.cn

${ }^{3}$ Professor, Department of Civil Engineering and Environmental Management, School of Computing, Engineering and Built Environment, Glasgow Caledonian University, Glasgow G4 0BA, Scotland, United Kingdom. E-mail: Ben.Zhang@gcu.ac.uk

${ }^{4} \mathrm{PhD}$ student, Department of Architecture and Civil Engineering, City University of Hong Kong, Tae Chee Avenue, Kowloon, Hong Kong, China. E-mail: dongya2222-x@my.cityu.edu.hk 


\section{Abstract}

Experimental tests were conducted on the composite rock-concrete specimens with granite, sandstone, and C30/C50 concrete to study the interfacial fracture process under three-point bending and four-point shear conditions. A unified interfacial crack initiation criterion expressed by the stress intensity factors (SIFs) was fitted by the SIFs corresponding to the interfacial crack initiation based on the experimental data. By combining with the fictitious crack model, the crack initiation criterion can be transformed into the crack propagation criterion by considering the contributions of the cohesive forces in the fracture process zone. By assessing the relationships of the interfacial propagation criterion and the maximum circumferential stress criteria of the rock and concrete, the potential interfacial crack propagation paths can be predicted. Furthermore, numerical analyses were carried out by introducing these criteria to simulate the complete fracture process of the rock-concrete interface, where the predicted $P-C M O D$ curves and crack trajectories showed good agreements with the experimental data. Finally, by taking a classic gravity dam in practical engineering as an example, the effects of the water levels, initial crack length and crack propagation length on the fracture behaviour of concrete, rock and their interface were investigated. The whole fracture processes for various fracture parameters of the rocks, concretes and their interfaces were simulated numerically. The results indicated that the employed method was effective for the safety assessment of the gravity dam and the application of these propagation criteria is convenient because only the initial fracture toughnesses of the rocks, concretes and their interfaces are required.

Keywords: rock-concrete interface; stress intensity factors; initial fracture toughness; crack propagation criterion; gravity dam 


\section{Introduction}

Concrete gravity dams play very significant roles in flood control, environmental conservation and power generation. In the stability analyses of gravity dams, sliding along a compressed discontinuity $[1,2]$, and crack initiation and propagation along the interface $[3,4]$ are understudied topics. In practice, many factors, including construction process, curing conditions, alkali aggregate reactions, hydrostatic loading, etc., could trigger the initiation of the interfacial cracks between rock foundations and concrete dams. The interfacial cracks are generally regarded as potential safety hazards to concrete dams because these cracks could propagate along different paths under various loading situations $[3,5-7]$ and govern the failure modes of these dams. In order to ensure safe operation of the dams in service, it is of significant importance for academic and engineering communities to investigate the interfacial fracture process and predict the failure modes of the concrete structures constructed on the rock foundations.

The bonding characteristics of the rock-concrete interfacial cracks have a close correlation with crack propagation paths [8]. The interfacial uniaxial tensile strength $f_{\mathrm{t}}$, the fracture energy $G_{\mathrm{f}}$ and the fracture toughnesses $K_{\mathrm{iC}}(i=1,2)$ are important mechanical and fracture parameters for evaluating the interfacial bonding properties. Here, $K_{1 \mathrm{C}}$ and $K_{2 \mathrm{C}}$ are the fracture toughnesses under mode-I and mode-II fractures, respectively. These parameters are influenced by the roughness degree $R_{\mathrm{a}}$ at the interface $[2,9,10]$ and are approximately linearly correlated with $R_{\mathrm{a}}$. Meanwhile, the mode-mixity ratio $\left(K_{2} / K_{1}\right)$, which reflects the stress status at the interfacial crack tip [1,11], showed a significant effect on the potential crack propagation paths [6,11-13], i.e. (1) the interfacial crack always propagates along the interface, (2) the interfacial crack kinks into the base material after partly propagating along the interface, and (3) the interfacial crack kinks into the base material once its 
initiation. Case (1) usually occur at a low mode-mixity ratio [6,14], while cases (2) and (3) are more likely to occur at high mode-mixity ratios [5].

In order to investigate the patterns of interfacial crack propagation, many experimental studies were carried out and several interfacial fracture criteria were proposed $[11,12]$. These criteria can be divided into three categories, namely stress-based [15], energy-based [16,17], and stress intensity factor (SIF)-based $[3,6,10,11,14,18]$. The stress-based criteria can effectively solve the stress concentration at the crack tip, and have been introduced to determine interfacial crack propagations and predict crack trajectories in the fracture analyses with respect to mode-I dominated $[3,6]$ and mixed mode $[5-7,11]$ fracture criteria. It should be noted that for the mode-I dominated fracture criteria, it usually assumed that the crack always propagates along the interface without branching. However, the scenario is different for the mixed mode fracture due to various potential propagation paths [5]. Therefore, based on the regression on the experimental data, Dong et al. [7] proposed a mixed mode criterion for the rock-concrete interfacial fracture by introducing the interfacial initial fracture toughness of mode-I, $K_{1 \mathrm{C}}^{\mathrm{ini}}$, to determine three potential crack propagation modes.

However, the abovementioned mixed mode criterion was derived from the experiment, where only C30 concrete and granite were employed. In practice, the value of $K_{1 \mathrm{C}}^{\mathrm{ini}}$ depends on the material properties of the two sides of the interface, as well as the junction of the two materials. It is not clear whether the fitted equation is still appropriate for the interfaces with the various strengths of concretes and different types of rocks. In additon, the mixed mode criterion was only validated by taking a comparion of the predicted results with those from the small-scale samples in the laboratory. The applicability of the criterion has not been verified with respect to the large-scale structures, like 
concrete gravatiy dams. In the previous research [7], it has been verified that under mixed mode stress field, the interfacial crack between the rock and concrete would be prone to propagate along the interface with a low $K_{2} / K_{1}$ ratio, and directly kink into the concrete after its initiation under the mixed mode fracture with a high $K_{2} / K_{1}$ ratio. However, it is not clearly clarified whether the crack would kink into the rock foundation for the gravity dams under the practical loading conditions. In addition, linear elastic fracture mechanics (LEFM) has been widely employed to determine the interfacial crack propagation path $[3,18,19]$ in the rock-concrete interfacial fracture analysis. According to the size effect law [20-23], the fracture behaviours in large size structures can be analysed using the LEFM theory because the size for the fracture process zone (FPZ) can be negligible compared to the dimensions of the structures. However, due to the effect of the cohesive force acting on the FPZ, the stress field at the interfacial crack tip will change, leading to the variations of the fracture path even for a large structure with a short FPZ length. Therefore, it is significant to clarify the effect of the cohesive force on the interfacial fracture behaviour, and a comparison of interfacial crack propagation process with/without considering cohesive force should be conducted in further study.

In addition, the study on the interfacial crack propagation can be also extended to the failure analysis of concrete at mesoscopic level, where the concrete can be subdivided into mortar, aggregate and their interface. Crack usually occurs at mesoscopic level around those weakest regions, i.e. the interfacial transition zones between aggregates and the surrounding cement paste or matrix [24-26]. The distinct material properties of these randomly distributed mesoscopic phases will significantly affect the crack initiation location, propagation path, failure mode and macroscopic response. For an in-depth insight into the failure mechanism of concrete at mesoscopic level, it is 
essential to investigate the crack initiation and propagation at interface and discover the effects of different phases and interfacial properties on the cracking patterns.

In line with this, following the previous study [7], the main aim of this study was to establish the crack propagation criterion for the rock-concrete interfaces formed by various types of concrete and rock. By using the derived criterion from the experiment, the numerical method was used to simulate the interfacial crack propagation process and predict the potential crack propagation paths. Meanwhile, taking a practical gravity dam as an example, the whole fracture behaviour was analysed by introducing the proposed criterion and the effects of materials properties, initial crack length, loading conditions and different criteria on the failure modes were discussed.

\section{Experimental program}

\subsection{Specimen preparation}

Two types of composite specimens were tested in this study, including rock-concrete composite prisms and beams, respectively. The dimensions of the composite prisms for the direct tension were $200 \mathrm{~mm} \times 100 \mathrm{~mm} \times 100 \mathrm{~mm}$, where the sizes of both concrete and rock blocks were $100 \mathrm{~mm} \times 100$ $\mathrm{mm} \times 100 \mathrm{~mm}$. The beam specimens were prepared for three-point bending (TPB) and four-point shearing (FPS) tests, and had sizes of $500 \mathrm{~mm} \times 100 \mathrm{~mm} \times 100 \mathrm{~mm}$. In the TPB tests, the lengths of the concrete and rock blocks were identical at $250 \mathrm{~mm}$ for each block. In order to cover a wide range of mode mixity ratios in the FPS tests, the pre-crack was expected to sustain different combined tension-shear stresses by changing the length of the rock blocks. The lengths of the rock block $\left(L_{\text {rock }}\right)$ were selected as $225 \mathrm{~mm}, 235 \mathrm{~mm}, 240 \mathrm{~mm}, 245 \mathrm{~mm}$ and $250 \mathrm{~mm}$, respectively, in this study. Accordingly, the lengths of the concrete block varied as $275 \mathrm{~mm}, 265 \mathrm{~mm}, 260 \mathrm{~mm}, 255 \mathrm{~mm}$ and $250 \mathrm{~mm}$ to keep the total lengths of the composite specimens being constant at $500 \mathrm{~mm}$. 

other one was fixed at the same position using cello tape (see Fig. 2(b)). Before testing, the cello tape

Fig. 1. Geometries of the specimens for the TPB and FPS tests (unit: $\mathrm{mm}$ ).

In order to reduce the dispersion of experimental results and promote the bond strength of the interface, rough interfaces were prepared using artificial groove lines on the contact surfaces of the rock sections. The groove lines were parallel to the diagonal lines of the interfacial cross-section with a depth of $3 \mathrm{~mm}$ (see Fig. 2(a)). For each composite beam, the length of the pre-crack, $a_{0}$, was $30 \mathrm{~mm}$. To obtain the pre-crack, two layers of polyvinyl chloride (PVC) film were put at the location of the pre-crack on the rock, where one PVC film was pasted on the surface of the rock using glue and the was pulled out to eliminate the bonding effect between the two layers of the PVC film.
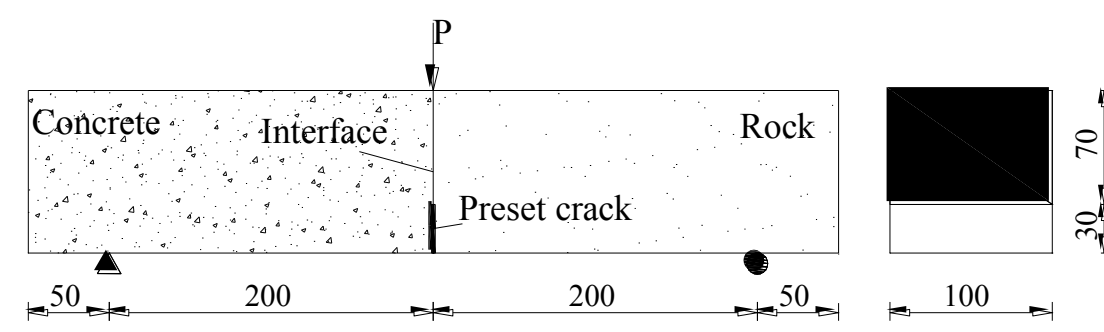

(a) TPB test
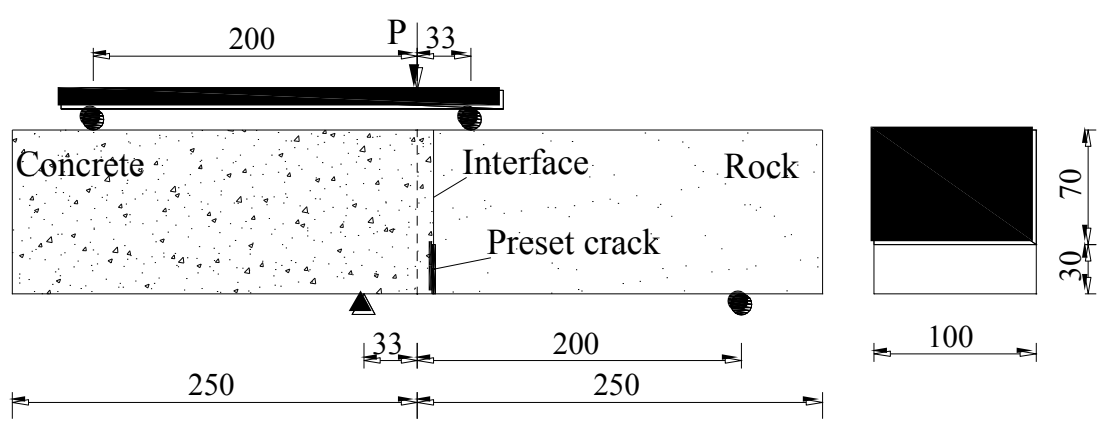

(b) FPS test 


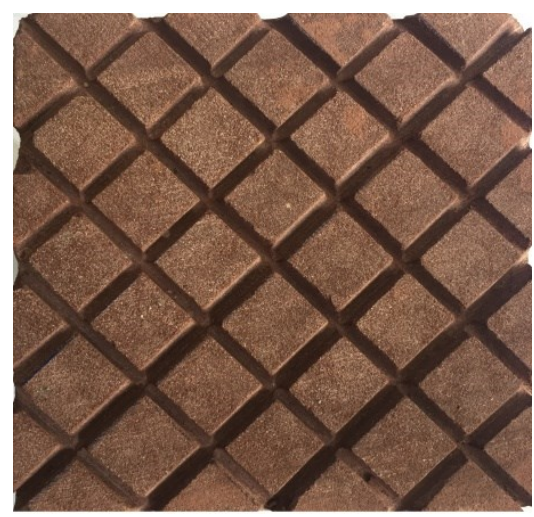

(a) Groove lines

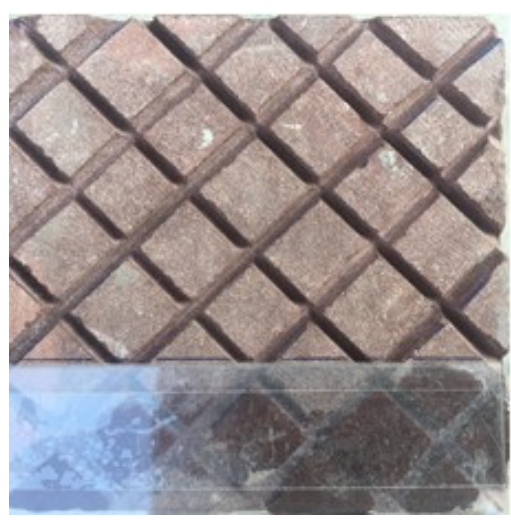

(b) Pre-crack preparation

Fig. 2. Preparation of rock-concrete interface.

\subsection{Material properties}

In this experimental study, the granite and sandstone employed were produced in Dalian, Liaoning Province of China. The mixture proportions of C30 and C50 concretes are listed in Table 1. The maximum aggregate sizes for the C30 and C50 concretes were $10 \mathrm{~mm}$ and $20 \mathrm{~mm}$, respectively. In addition, $42.5 \mathrm{~N}$ and $52.5 \mathrm{~N}$ ordinary Portland cements were used for manufacturing the $\mathrm{C} 30$ and C50 concretes. The interfaces of the composite specimens were divided into three categories: C50granite, C30-sandstone and C50-sandstone, denoted as C50-G, C30-S and C50-S. The test specimens were demoulded 2 days after casting and moved into a standard curing room with $23^{\circ} \mathrm{C}$ and $95 \%$ relative humidity $(\mathrm{RH})$ until the age of 28 days.

Table 1 The mix proportions of the concretes $\left(\right.$ Unit: $\mathrm{kg} / \mathrm{m}^{3}$ ).

\begin{tabular}{ccccc}
\hline Concrete & Cement & Water & Sand & Aggregate \\
\hline C30 & $327(42.5 \mathrm{~N})$ & 195 & 657 & $1204\left(d_{\max }=10 \mathrm{~mm}\right)$ \\
C50 & $466(52.5 \mathrm{~N})$ & 214 & 593 & $1102\left(d_{\max }=20 \mathrm{~mm}\right)$ \\
\hline
\end{tabular}

Note: $d_{\max }=$ maximum size of the aggregate.

The measured mechanical properties of the concretes, rocks and rock-concrete interfaces are summarised in Table 2, where $E$ is the elastic modulus, $\rho$ is the density, $v$ is the Poisson's ratio, $f_{\mathrm{t}}$ is the uniaxial tensile strength, $f_{\mathrm{c}}$ is the uniaxial compressive strength, $P_{\text {ini }}$ is the initial cracking load, $P_{\max }$ is 
170 the peak load, $K_{1 \mathrm{C}}^{\mathrm{ini}}$ is the initial fracture toughness of mode I, and $G_{\mathrm{If}}$ is the fracture energy.

171 Table 2 Material properties of the concretes and rocks.

\begin{tabular}{cccccccccc}
\hline Materials & $\begin{array}{c}E \\
(\mathrm{GPa})\end{array}$ & $\begin{array}{c}\rho \\
\left(\mathrm{kg} / \mathrm{m}^{3}\right)\end{array}$ & $v$ & $\begin{array}{c}f_{\mathrm{t}} \\
(\mathrm{MPa})\end{array}$ & $\begin{array}{c}f_{\mathrm{c}} \\
(\mathrm{MPa})\end{array}$ & $\begin{array}{c}P_{\text {ini }} \\
(\mathrm{kN})\end{array}$ & $\begin{array}{c}P_{\max } \\
(\mathrm{kN})\end{array}$ & $\begin{array}{c}K_{1 \mathrm{C}}^{\text {ini }} \\
\left(\mathrm{MPa} \cdot \mathrm{m}^{1 / 2}\right)\end{array}$ & $\begin{array}{c}G_{\text {If }} \\
(\mathrm{N} / \mathrm{m})\end{array}$ \\
\hline C30 concrete & 29.05 & 2450 & 0.236 & 1.82 & 47.11 & 2.327 & 3.858 & 0.448 & 103.61 \\
C50 concrete & 32.44 & 2450 & 0.175 & 2.71 & 57.14 & 2.825 & 4.663 & 0.543 & 131.67 \\
Sandstone & 9.13 & 2500 & 0.284 & 1.65 & 48.12 & 1.758 & 2.123 & 0.338 & 120.30 \\
Granite & 34.58 & 2750 & 0.160 & 6.59 & 164.72 & 9.308 & 10.233 & 1.835 & 219.24 \\
\hline
\end{tabular}

\subsection{The TPB and FPS tests}

A closed loop servo-controlled MTS (Mechanical Testing and Simulation) testing machine with a capacity of $250 \mathrm{kN}$ was employed for the TPB and FPS tests, as shown in Fig. 3. The tests adopted the displacement-control mode at a displacement rate of $0.024 \mathrm{~mm} / \mathrm{min}$. The loading point displacement $\delta$, and the crack mouth opening and sliding displacements, $C M O D$ and $C M S D$, were measured by using clip gauges. To measure the initial cracking load, two strain gauges were symmetrically put on both sides of the specimen, $5 \mathrm{~mm}$ away from the tip of the pre-crack in the ligament. The strain readings would drop rapidly due to the sudden release of the stored strain energy once the pre-crack initiates. Thus, $P_{\text {ini }}$ can be obtained by monitoring the variations of the strains.

The experimental results of the TPB and FPS tests are listed in Tables 3 and 4, respectively.

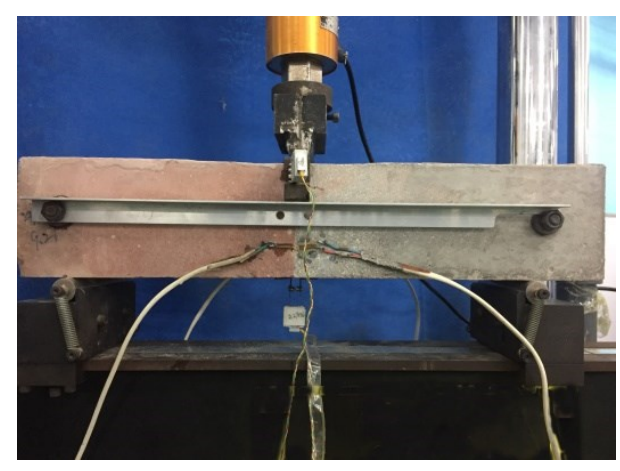

(a) TPB test

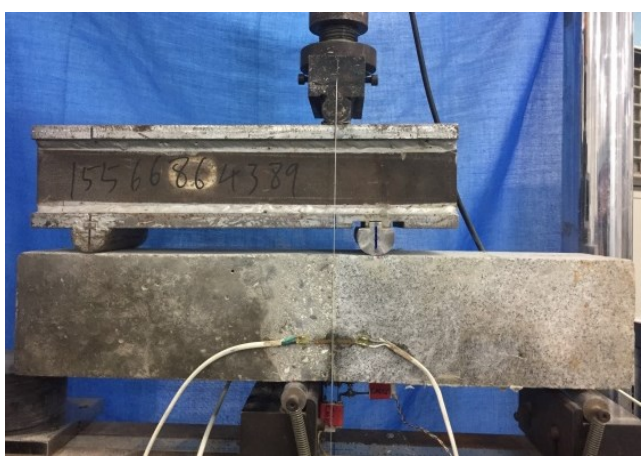

(b) FPS test

Fig. 3. Set-ups for the TPB and FPS tests. 
186 Table 3 Experimental results for the TPB tests.

\begin{tabular}{|c|c|c|c|c|c|c|}
\hline Specimen & $P_{\text {ini }}(\mathrm{kN})$ & $P_{\text {max }}(\mathrm{kN})$ & $f_{\mathrm{t}}(\mathrm{MPa})$ & $K_{1 \mathrm{C}}^{\mathrm{ini}}$ & $\left(\mathrm{MPa} \cdot \mathrm{m}^{1 / 2}\right)$ & $G_{\text {If }}(\mathrm{N} / \mathrm{m})$ \\
\hline TPB-C50-G & 1.588 & 2.044 & 1.588 & & 0.395 & 31.448 \\
\hline TPB-C30-S & 1.152 & 1.522 & 1.152 & & 0.297 & 20.513 \\
\hline TPB-C50-S & 1.415 & 1.796 & 1.415 & & 0.350 & 33.205 \\
\hline
\end{tabular}

187 188

Table 4 Experimental results for the FPS tests.

\begin{tabular}{cccccccc}
\hline Specimen & $\begin{array}{c}L_{\text {rock }} \\
(\mathrm{mm})\end{array}$ & $\begin{array}{c}P_{\text {ini }} \\
(\mathrm{kN})\end{array}$ & $\begin{array}{c}P_{\text {max }} \\
(\mathrm{kN})\end{array}$ & $\begin{array}{c}K_{1}^{\text {ini }} \\
\left(\mathrm{MPa} \cdot \mathrm{m}^{1 / 2}\right)\end{array}$ & $\begin{array}{c}K_{2}^{\text {ini }} \\
\left(\mathrm{MPa} \cdot \mathrm{m}^{1 / 2}\right)\end{array}$ & $\left|K_{2}^{\text {ini }} / K_{1}^{\text {ini }}\right|$ & $\begin{array}{c}\text { Failure } \\
\text { mode }\end{array}$ \\
\hline C50-G-225 & 225 & 12.245 & 14.050 & 0.394 & 0.140 & 0.355 & $\mathrm{I}$ \\
C50-G-235 & 235 & 16.107 & 20.891 & 0.343 & 0.243 & 0.708 & $\mathrm{I}$ \\
C50-G-240 & 240 & 20.431 & 31.782 & 0.314 & 0.351 & 1.118 & $\mathrm{I}$ \\
C50-G-245 & 245 & 26.162 & 35.334 & 0.231 & 0.505 & 2.186 & $\mathrm{I}$ \\
C50-G-250 & 250 & 29.689 & 40.153 & 0.049 & 0.645 & 13.163 & $\mathrm{I}$ \\
C30-S-225 & 225 & 8.657 & 10.825 & 0.277 & 0.103 & 0.372 & $\mathrm{I}$ \\
C30-S-235 & 235 & 10.816 & 13.007 & 0.251 & 0.173 & 0.689 & $\mathrm{~K}$ \\
C30-S-240 & 240 & 12.063 & 16.372 & 0.211 & 0.211 & 1.000 & $\mathrm{~K}$ \\
C30-S-245 & 245 & 13.182 & 18.457 & 0.145 & 0.249 & 1.717 & $\mathrm{~K}$ \\
C30-S-250 & 250 & 15.897 & 21.543 & 0.063 & 0.317 & 5.032 & $\mathrm{~K}$ \\
C50-S-225 & 225 & 8.746 & 11.503 & 0.287 & 0.106 & 0.369 & $\mathrm{~K}$ \\
C50-S-235 & 235 & 9.604 & 13.374 & 0.226 & 0.153 & 0.683 & $\mathrm{~K}$ \\
C50-S-240 & 240 & 10.308 & 14.351 & 0.181 & 0.180 & 0.996 & $\mathrm{~K}$ \\
C50-S-245 & 245 & 12.777 & 15.823 & 0.143 & 0.240 & 1.678 & $\mathrm{~K}$ \\
C50-S-250 & 250 & 13.935 & 16.622 & 0.058 & 0.277 & 4.776 & $\mathrm{~K}$ \\
\hline
\end{tabular}

Note: Failure mode I: the interfacial crack always propagates along interface; Failure mode K: the interfacial crack kinks into rock once its initiation.

In Table 3, Specimen TPB-C50-G denotes the TPB specimen with the interface between the C50 concrete and granite. In Table 4, Specimen C30-S-225 denotes the FPS specimen with the interface between $\mathrm{C} 30$ concrete and sandstone, and the rock block length $L_{\text {rock }}=225 \mathrm{~mm}$. There were two failure modes observed in the tests, i.e. the interfacial crack always propagates along the interface (denoted as mode I), and the interfacial crack kinks into the rock after its initiation (denoted as mode $\mathrm{K})$.

The SIFs, $K_{1}$ and $K_{2}$, of bi-material interface crack were calculated using the displacement 
extrapolation method [27], and the calculation details can be referred to literature [7]. $K_{1}$ and $K_{2}$ can 199 be written as $K_{1}^{\mathrm{ini}}$ and $K_{2}^{\mathrm{ini}}$ corresponding to $P_{\text {ini. }}$ According to the results for the interface 200 between concrete and sandstone in Table 3, the interfacial bond properties, e.g. $f_{\mathrm{t}}, K_{1}^{\mathrm{ini}}$ and $G_{\mathrm{If}}$, 201 increased with the increasing concrete strength. This indicates that the cement mortar with higher 202 strength can provide better bonding at the interface. Meanwhile, if the same strength concrete was selected, the bond surface of the granite can increase the bonding effect compared with that of the sandstone. In addition, only failure mode I was observed for the interfaces between the concrete and granite, i.e. the crack propagated throughout the interface (see Table 4). For the interface between the concrete and sandstone, however, the other failure mode $\mathrm{K}$, where the crack kinked into the sandstone, was also observed (see Table 4). The mechanism for the various interfacial crack propagation paths are to be discussed in the following section.

\section{SIF-based crack propagation criterion for rock-concrete interface}

\subsection{Introduction of the criterion}

According to the previous experimental investigations by Dong et al. [7], the interfacial crack

212 initiation under the mixed mode fracture can be determined from

$$
\left(\frac{K_{1}}{K_{1 \mathrm{C}}^{\mathrm{ini}}}\right)^{2}+\left(\frac{K_{2}}{1.6 K_{1 \mathrm{C}}^{\mathrm{ini}}}\right)^{2}=1
$$

The complete fracture process can be considered as the new interfacial crack initiates continually, so that the crack initiation criterion can be employed to determine the interfacial crack propagation by combining with the fictitious crack model [28]. In this manner, Eq. (1) can be written as follows by considering the cohesive force acting on the FPZ. 


$$
K_{1,2}^{*}=\sqrt{\left(\frac{K_{1}^{\mathrm{P}}-K_{1}^{\sigma, \tau}}{1}\right)^{2}+\left(\frac{K_{2}^{\mathrm{P}}-K_{2}^{\sigma, \tau}}{1.6}\right)^{2}}=K_{1 \mathrm{C}}^{\mathrm{ini}}
$$

219 where $K_{1}^{\mathrm{P}}$ and $K_{2}^{\mathrm{P}}$ are the SIFs of modes I and II caused by the external load, while $K_{1}^{\sigma, \tau}$ and $K_{2}^{\sigma, \tau}$ are the SIFs of modes I and II caused by the cohesive tensile and shear stresses on the FPZ, $\sigma$ and $\tau$. Meanwhile, the maximum circumferential stress criterion [3,29] was introduced to determine the

$$
K_{\mathrm{I}, \mathrm{II}}^{*}=\frac{\sqrt{\left(K_{1}^{\mathrm{P}}-K_{1}^{\sigma, \tau}\right)^{2}+\left(K_{2}^{\mathrm{P}}-K_{2}^{\sigma, \tau}\right)^{2}}}{2 \cosh (\varepsilon \pi)} W_{\mathrm{j}}\left[2 \cos \left(\frac{\theta_{0}}{2}+\gamma\right)-\left(\cos \theta_{0}+2 \varepsilon \sin \theta_{0}\right) \cos \left(\frac{\theta_{0}}{2}-\gamma\right)+\frac{1}{W_{\mathrm{j}}} \cos \left(\frac{3}{2} \theta_{0}+\gamma\right)\right]=K_{\mathrm{Ij}}^{\mathrm{ini}}
$$

where $K_{\mathrm{Ij}}^{\mathrm{ini}}$ is the initial mode I fracture toughness of material $j, j$ denotes rock or concrete, and $\theta_{0}$ is the kinking angle [7]. The parameters $\gamma, W_{j}$ and $\varepsilon$ in Eq. (3) are given as

$$
\begin{gathered}
\gamma= \begin{cases}\arctan \left(\frac{K_{2}^{\mathrm{P}}-K_{2}^{\sigma, \tau}}{K_{2}^{\mathrm{P}}-K_{2}^{\sigma, \tau}}\right) & K_{1}>0 \\
\pi+\arctan \left(\frac{K_{2}^{\mathrm{P}}-K_{2}^{\sigma, \tau}}{K_{2}^{\mathrm{P}}-K_{2}^{\sigma, \tau}}\right) & K_{1}<0\end{cases} \\
W_{\mathrm{j}}= \begin{cases}e^{-\varepsilon\left(\pi-\theta_{0}\right)} & j=1 \\
e^{\varepsilon\left(\pi+\theta_{0}\right)} & j=2\end{cases}
\end{gathered}
$$

$$
\text { bimaterial constant } \varepsilon=\frac{1}{2 \pi} \ln \left(\frac{\frac{\kappa_{1}}{\mu_{1}}+\frac{1}{\mu_{2}}}{\frac{\kappa_{2}}{\mu_{2}}+\frac{1}{\mu_{1}}}\right)
$$

228 with

$$
\text { shear modulus } \mu_{\mathrm{i}}=\frac{E_{\mathrm{i}}}{2\left(1+v_{\mathrm{i}}\right)} \quad(i=1,2)
$$

$$
\text { elastic constant } \kappa_{\mathrm{i}}= \begin{cases}\left(3-v_{\mathrm{i}}\right) /\left(1+v_{\mathrm{i}}\right) & \text { (plane stress) } \\ \left(3-v_{\mathrm{i}}\right) & \text { (plane strain) }\end{cases}
$$

where $E_{\mathrm{i}}$ is the elastic modulus for material $i$, and $v_{\mathrm{i}}$ is the Poisson's ratio for material $i$. 
judged as follows:

(i) If $K_{\mathrm{I}, \mathrm{II}}^{*}<K_{\mathrm{Ij}}^{\mathrm{ini}}$ and $K_{1,2}^{*}<K_{\mathrm{lC}}^{\mathrm{ini}}$, the crack does not propagate; experimental study.

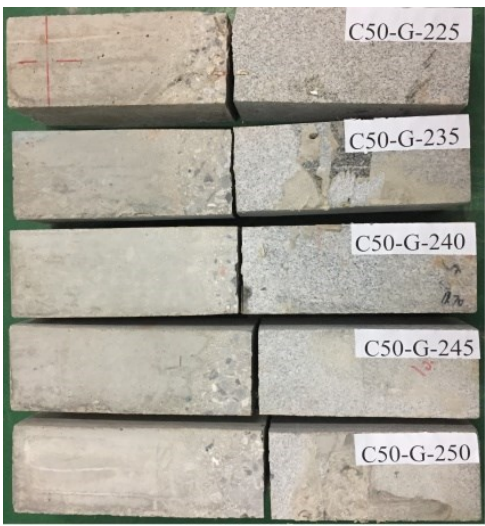

(a) C50-G series specimens

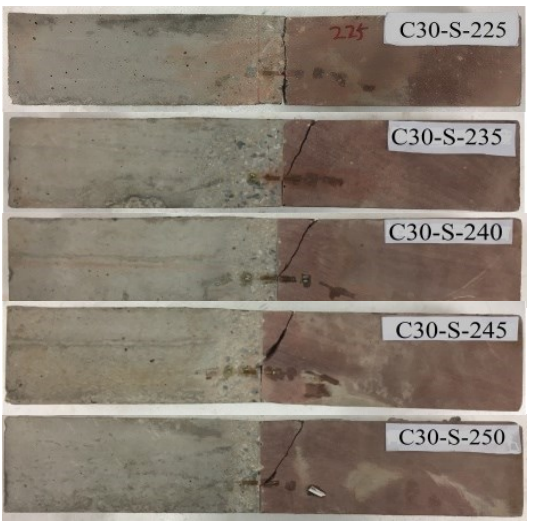

(b) C30-S series specimens

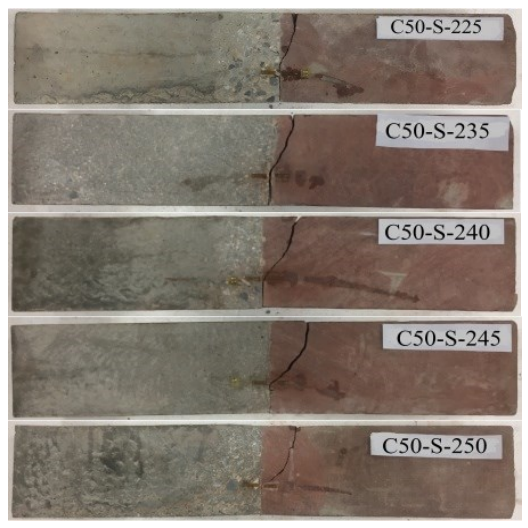

(c) C50-S series specimens 
Since Eq. (1) represents the criterion for determining the interfacial crack initiation, the points of the normalised terms $K_{1}^{\mathrm{ini}} / K_{1 \mathrm{C}}^{\mathrm{ini}}$ and $K_{2}^{\mathrm{ini}} / K_{1 \mathrm{C}}^{\mathrm{ini}}$ for the C50-G and C30-S-225 series specimens could be employed to fit the initiation equation of the interfacial crack. Accordingly, the points with coordinates of $K_{2}^{\mathrm{ini}} / K_{1 \mathrm{C}}^{\mathrm{ini}}$ and $K_{1}^{\mathrm{ini}} / K_{1 \mathrm{C}}^{\mathrm{ini}}$ for various interfaces are shown in Fig. 5, indicating good agreements with Eq. (1), though only two groups of points were provided for the C30-S series specimens. Therefore, it seems that the rock-concrete interfacial initiation criterion was not affected by the concrete strength and types of rock, i.e. Eq. (1) can be used to determine the rock-concrete interfacial initiation for a wide application.

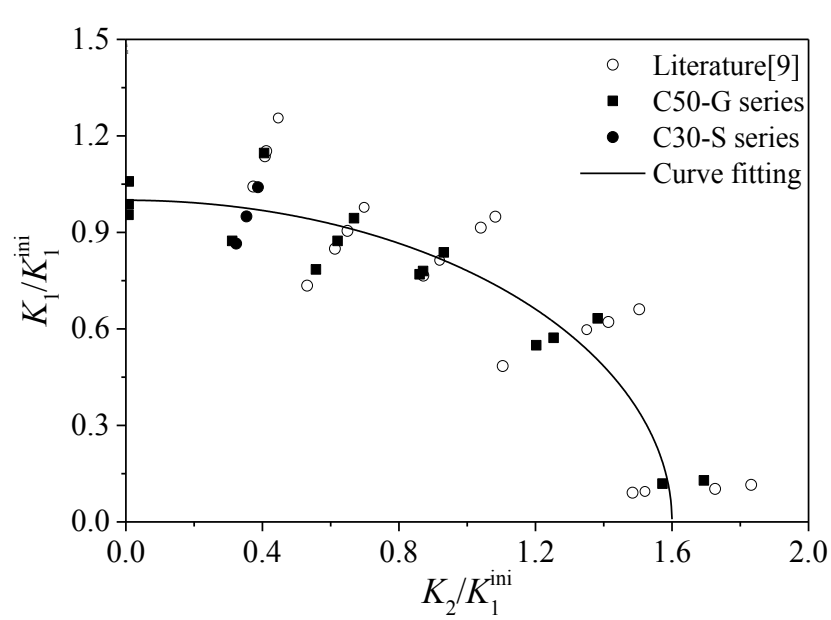

Fig. 5. Fitting curve with the experimental data

Fig. 6 shows the $K_{1}-K_{2}$ relationships of the criteria with $K_{\mathrm{I}, \mathrm{II}}^{*}=K_{\mathrm{Ij}}^{\mathrm{ini}}$ for the rocks and $K_{1,2}^{*}=K_{1 \mathrm{C}}^{\mathrm{ini}}$ 262 for the interface, where the curves of $K_{\mathrm{I}, \mathrm{II}}^{*}=K_{\mathrm{Ij}}^{\mathrm{ini}}$ for granite and sandstone can be determined using 263 Eq. (3) and the curves of $K_{1,2}^{*}=K_{1 \mathrm{C}}^{\mathrm{ini}}$ for the interfaces can be determined by Eq. (2). It should be noted that according to the experimental design in this study, the interfacial cracks under the FPS loading shown in Fig. 3(b) cannot propagate into the concrete. Therefore, only the relationships between the rocks and interfaces were discussed here. It can be seen from Fig. 6 that the curve of 
$K_{\mathrm{I}, \mathrm{II}}^{*}=K_{\mathrm{Ij}}^{\mathrm{ini}}=1.835 \mathrm{MPa} \cdot \mathrm{m}^{1 / 2}$ for the granite was always outside those of $K_{1,2}^{*}=K_{1 \mathrm{C}}^{\mathrm{ini}}=0.297$ $\mathrm{MPa} \cdot \mathrm{m}^{1 / 2}, 0.350 \mathrm{MPa} \cdot \mathrm{m}^{1 / 2}$ and $0.395 \mathrm{MPa} \cdot \mathrm{m}^{1 / 2}$ for the rock-concrete interfaces. This indicates that for the $\mathrm{C} 50-\mathrm{G}$ series specimens under any loading conditions, the crack would not propagate into the granite from the interfaces. This has also been validated by the experimental failure modes of the C50-G series specimens as shown in Fig. 4(a).

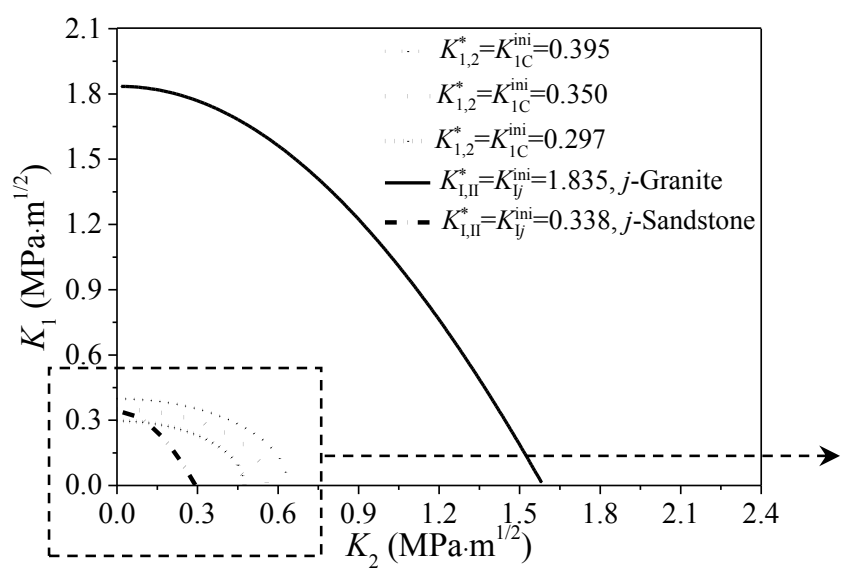

(a) Concrete-granite interface

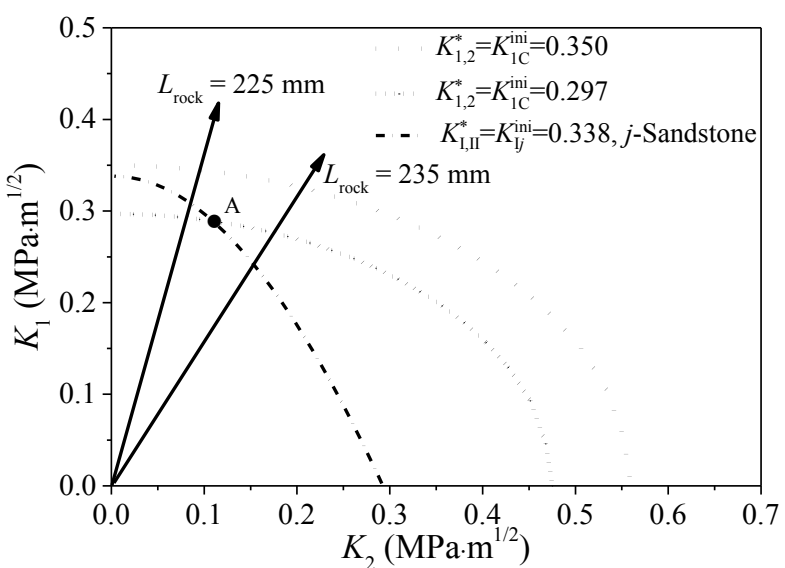

(b) Concrete-sandstone interface

Fig. 6. Relationships between $K_{1,2}^{*}=K_{1 \mathrm{C}}^{\mathrm{ini}}$ and $K_{\mathrm{I}, \mathrm{II}}^{*}=K_{\mathrm{Ij}}^{\mathrm{ini}}$ for different interfaces.

Similarly, the curve at $K_{1,2}^{*}=K_{1 \mathrm{C}}^{\mathrm{ini}}=0.350 \mathrm{MPa} \cdot \mathrm{m}^{1 / 2}$ for the interface of the $\mathrm{C} 50-\mathrm{S}$ series specimens was always outside the curve at $K_{\mathrm{I}, \mathrm{II}}^{*}=K_{\mathrm{Ij}}^{\mathrm{ini}}=0.338 \mathrm{MPa} \cdot \mathrm{m}^{1 / 2}$ for the sandstone (see Fig.

6). This indicates that for the C50-S series specimens under any loading conditions, the interfacial crack could propagate into the sandstone after its initiation. This has also been validated by the experimental failure modes of the C50-S series specimens as shown in Fig. 4(c).

In contrast, there was an intersection point between the curve at $K_{\mathrm{I}, \mathrm{II}}^{*}=K_{\mathrm{Ij}}^{\mathrm{ini}}=0.338 \mathrm{MPa} \cdot \mathrm{m}^{1 / 2}$ for the sandstone and the curve at $K_{1,2}^{*}=K_{1 \mathrm{C}}^{\mathrm{ini}}=0.297 \mathrm{MPa} \cdot \mathrm{m}^{1 / 2}$ for the C30-S series specimens, corresponding to the $K_{2} / K_{1}$ ratio of 0.565 (see Point A in Fig. 6). Therefore, the interfacial crack could directly initiate and propagate into the sandstone when $K_{2}^{\mathrm{ini}} / K_{1}^{\mathrm{ini}}<0.565$, but would initiate and 
284 propagate along the interface when $K_{2}^{\mathrm{ini}} / K_{1}^{\mathrm{ini}}>0.565$. According to the calculated results listed in 285 Table 4, the ratio $K_{2}^{\text {ini }} / K_{1}^{\text {ini }}=0.376<0.565$ for the C30-S-225 series specimens, indicating that for 286 those specimens, the interfacial crack would initiate and propagate along the interface. For the others 287 C30-S series specimens, the interfacial crack would propagate into the sandstone after its initiation. 288 This has been validated by the experimental failure modes of the C30-S series specimens as shown in 289 Fig. 4(b).

The numerical analyses based on the fictitious crack model [30] were carried out to verify the applicability of this criterion. In this study, ANSYS FE code was employed to simulate the complete process of crack propagation under the TPB and FPS loading conditions, with the flow chart shown in Fig. 7. In the fracture analysis, a singular element was used to calculate the SIF at the crack tip.

294 Because high-stress gradients exist in the region around the crack tip, special attention should be paid to that region. Therefore, a circle was set at the tip of the crack, where the crack tip is the centre of the circle and the radius of the circle was $1 \mathrm{~mm}$ for the beam specimens. Meanwhile, the first row of elements around the crack tip had a radius of $1 / 6 \mathrm{~mm}$, and their mid-side nodes were placed at the quarter points, with a radius of 1/24 mm. A re-meshing method [31] was used in the simulation when a new crack path with a propagated length was developed. Taking Specimen C30-S-245 under FPS as an example, different fracture stages under loading are shown in Fig. 8. 


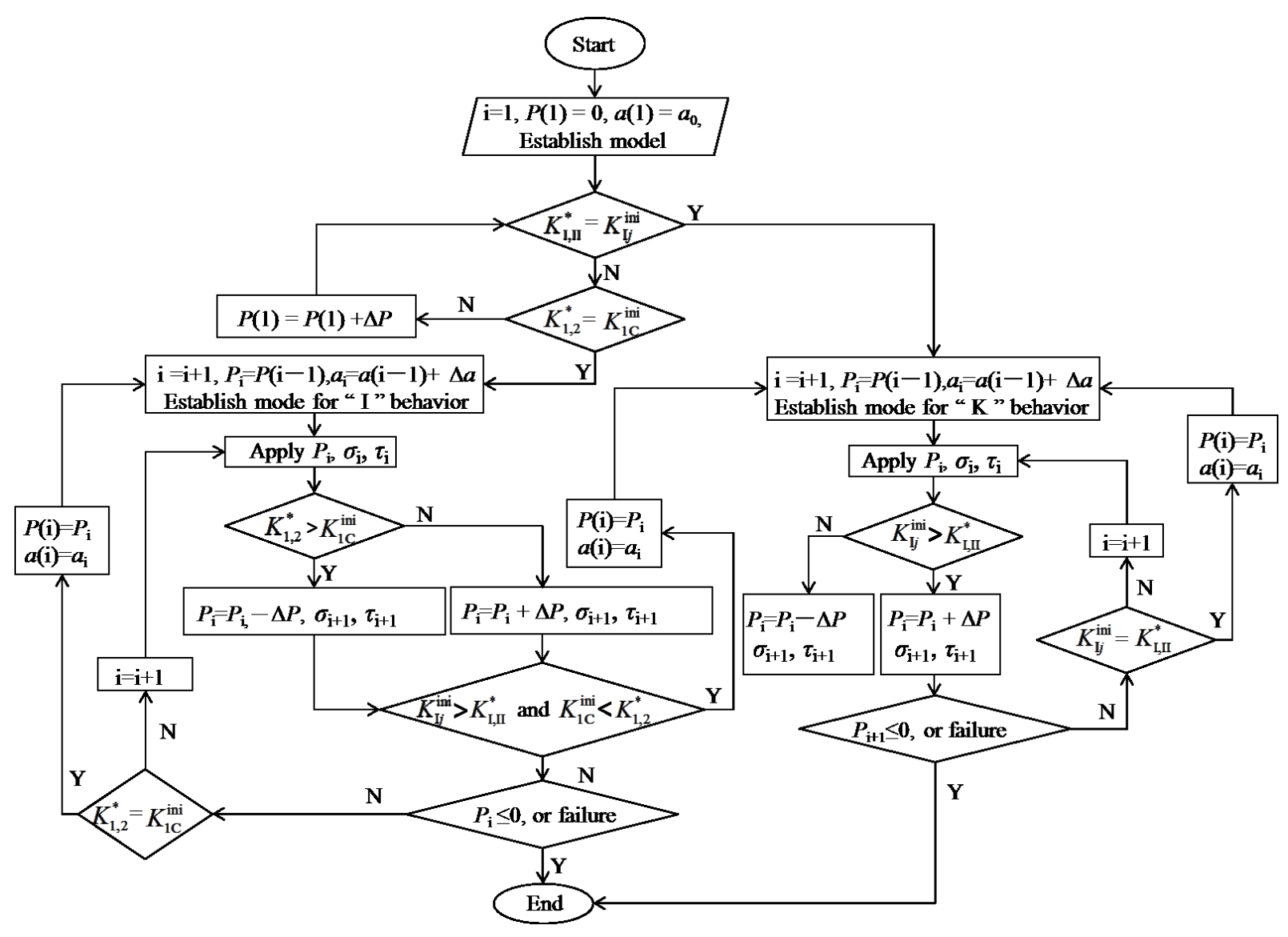

Fig. 7. Simulation flow chart for crack propagation at interface.

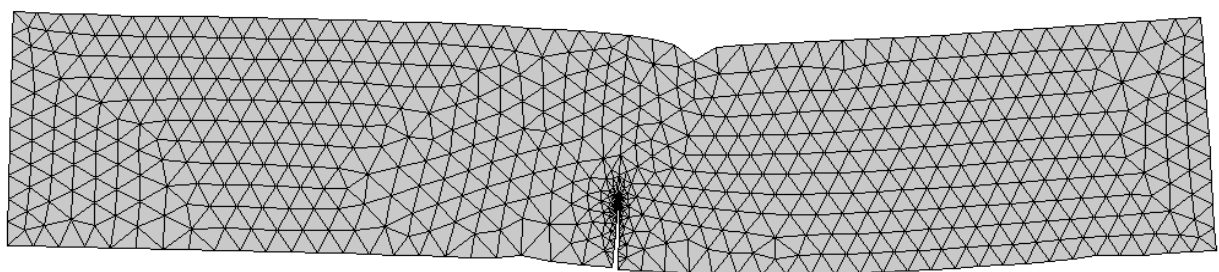

(a) Crack initiation

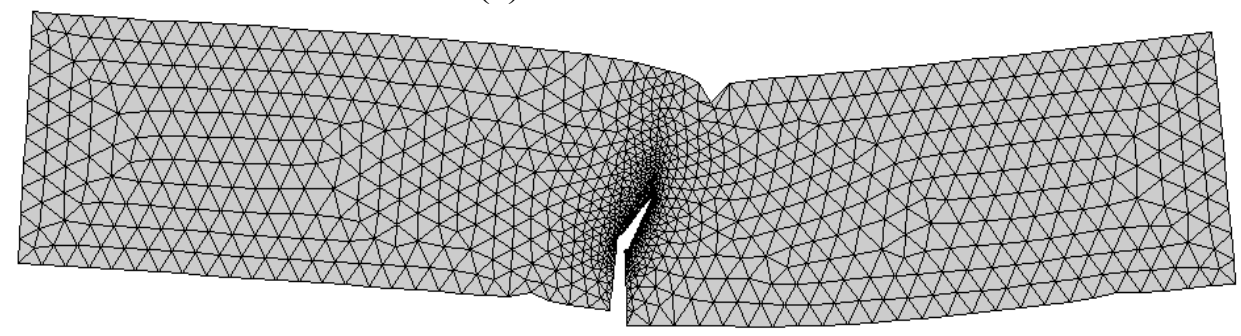

(b) Unstable propagation 


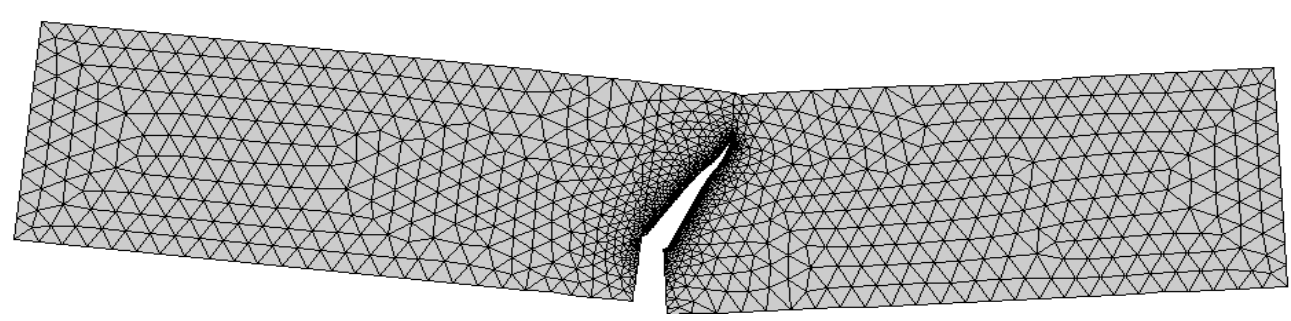

(c) Failure

Fig. 8. Deformed meshes of Specimen C30-S-245 at different fracture stages.

The numerical simulation process is summarised as follows.

1. Establish the FE model with an initial crack length $a_{0}$ and apply the load $P(i)(i=1,2, \ldots)$ until $K_{1,2}^{*}=K_{1 \mathrm{C}}^{\mathrm{ini}}$ or $K_{\mathrm{I}, \mathrm{II}}^{*}=K_{\mathrm{Ij}}^{\mathrm{ini}}$ where $i$ represents the increment of the crack length during iterations. 2. If $K_{\mathrm{I}, \mathrm{II}}^{*}=K_{\mathrm{Ij}}^{\mathrm{ini}}$, follow Procedures 2(a) to 2(d), otherwise follow Procedure 3 .

2(a) Indicate the crack kinks into the sandstone in the direction $\theta$ with the increment of $\Delta a$, and re-establish model $i=i+1$ and $\operatorname{set} P(i)=P(i-1)$.

2(b) Apply the load $P(i)$ and calculate the cohesive stresses $\sigma(i)$ and $\tau(i)$ according to the cohesive tensile/shear traction - displacement relationships.

2(c) Calculate $K_{1}^{\mathrm{P}}, K_{1}^{\sigma, \tau}, K_{2}^{\mathrm{P}}$ and $K_{2}^{\sigma, \tau}$ by adjusting the load $P(i+1)=P(i) \pm n \cdot \Delta P(n=1,2, \ldots)$ until Eq. (3) is satisfied.

2(d) Repeat Procedures 2(a) to 2(c), until $P(i) \leq 0$ or the specimen failed.

3. If $K_{1,2}^{*}=K_{1 \mathrm{C}}^{\mathrm{ini}}$, follow Procedures 3(a) to 3(d).

3(a) Indicate the crack propagates along the interface with the increment of $\Delta a$, and re-establish mode $i=i+1$ and set $P(i)=P(i-1)$.

3(b) Apply the load $P(i)$ and calculate the cohesive stresses $\sigma(i)$ and $\tau(i)$ according to the cohesive tensile/shear traction - displacement relationships.

3(c) Calculate $K_{1}^{\mathrm{P}}, K_{1}^{\sigma, \tau}, K_{2}^{\mathrm{P}}$ and $K_{2}^{\sigma, \tau}$ by adjusting load $P(i+1)=P(i) \pm n \cdot \Delta P(n=1,2, \ldots)$ until Eq. (2) or Eq. (3) is satisfied. If Eq. (3) is satisfied, go to 2(a), while if Eq. (2) is satisfied, go to 3(d). 
3(d) Repeat Procedures 3(a) to 3(c), until $P(\mathrm{i}) \leq 0$ or specimens failed. Finish.

The interface elements targe 168 and conta172 were employed in the simulations. The cohesive forces acting on the FPZ were applied based on the cohesive traction-displacement relationships. The cohesive traction-displacement relationships including tension softening $(w-\sigma)$ and shear softening $\left(w_{\mathrm{s}}-\tau\right)$ are shown in Figs. 9(a) and (b), where $w$ and $w_{\mathrm{s}}$ denote the crack opening and sliding displacements, and $\sigma$ and $\tau$ denote the tension and shear stresses acting on the FPZ. $G_{\text {IIf }}$ is the fracture energy for the mode II fracture, which is equal to $2 G_{\text {If. }}$ If the cracking opening/sliding displacements, $w$ and $w_{\mathrm{s}}$, are larger than the corresponding critical values, $w_{0}$ and $w_{\mathrm{s} 0}$, the opening/sliding stress-free zones would be formed.

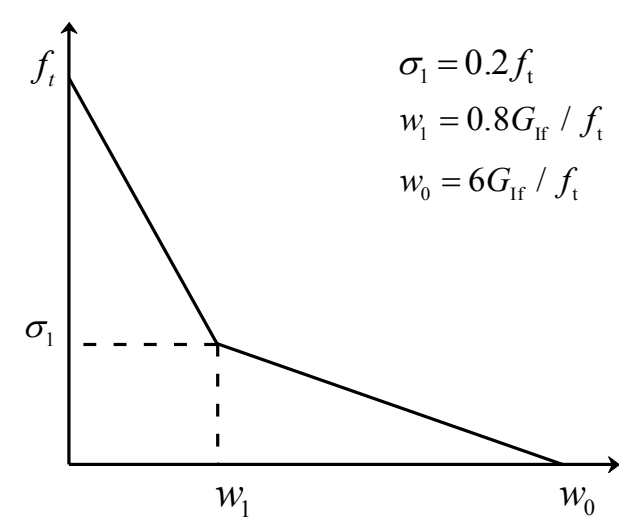

(a) Tension-softening [10]

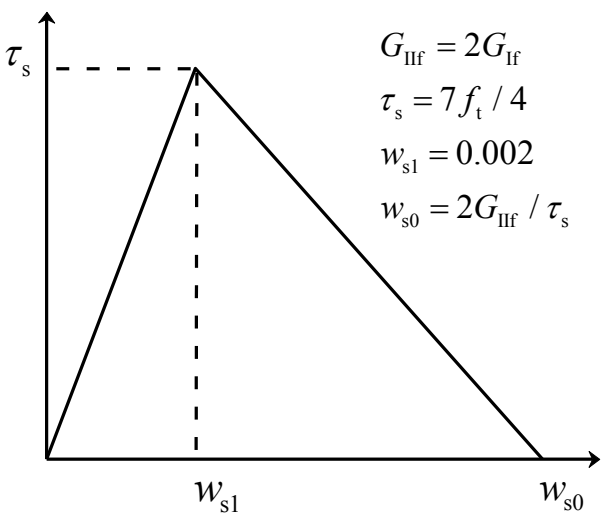

(b) Shear-softening [6]

Fig. 9. Cohesive tension traction and shear stress versus displacement relationships.

By performing the iteration process shown in Fig. 7, the complete interfacial crack propagation can be obtained numerically. Taking Specimens TPB-C30-S, C30-S-225, C50-S-240, C50-G-240 as examples, Fig. 10 illustrates the comparisons of the experimental $P$-CMOD curves with the numerical results. 


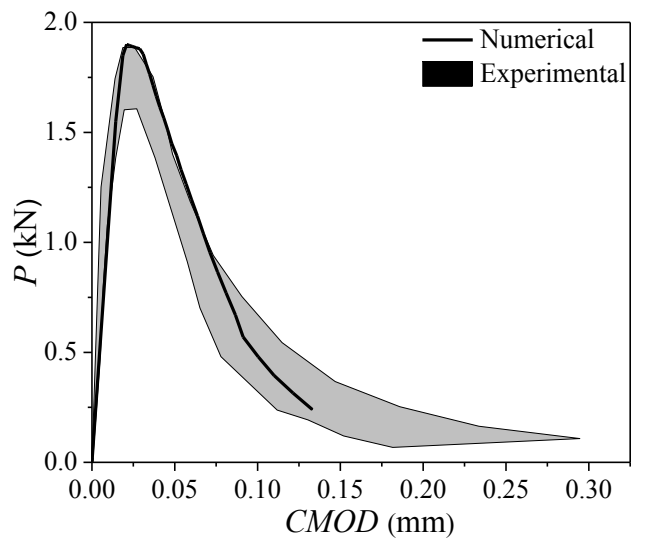

(a) Specimen TPB-C30-S

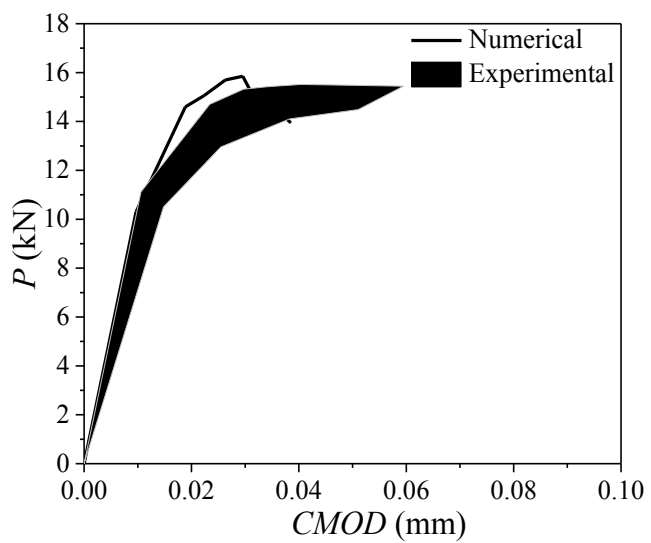

(c) Specimen C50-S-240

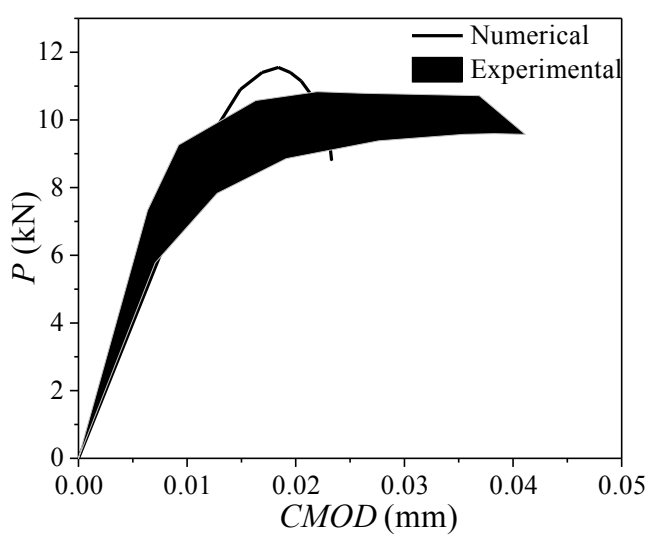

(b) Specimen C30-S-225

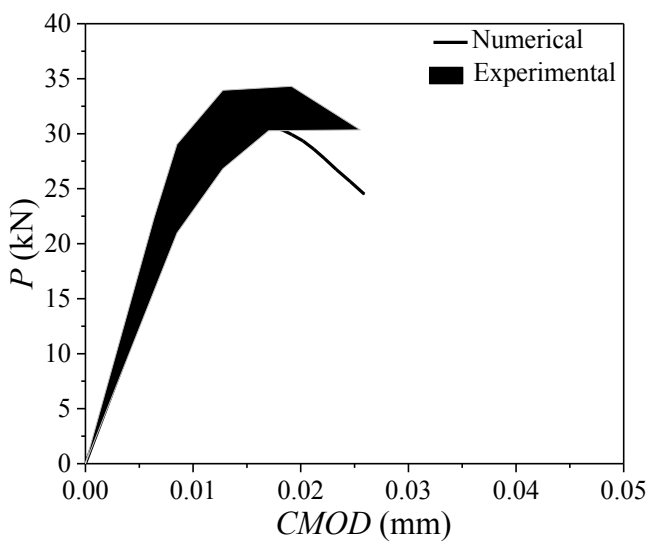

(d) Specimen C50-G-240

Fig. 10. Comparisons of the $P-C M O D$ curves on typical TPB and FPS series specimens.

For the interfacial crack kinking into the sandstone, Figs. 11(a) and (b) show the comparisons of the crack propagation trajectories between the numerical predictions and experimental measurements for Specimens C30-S-235 and C50-S-250, respectively. By comparing the results in these figures, fairly good agreements can be observed, which verifies the numerical method together with the criterion. 


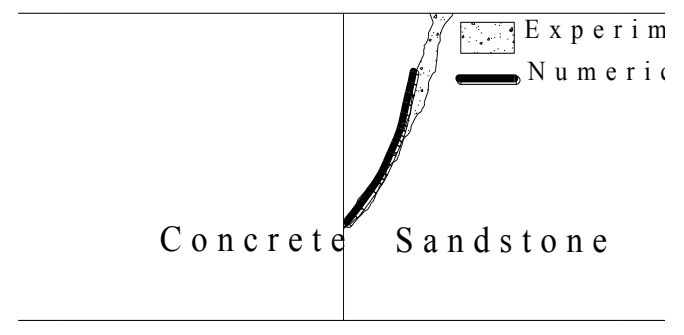

(a) Specimen C30-S-235

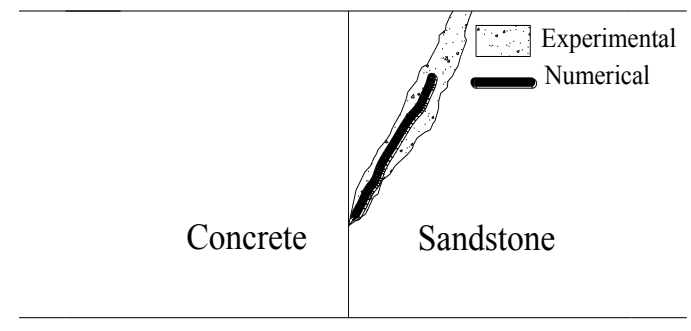

(b) Specimen C50-S-250

Fig. 11. Comparisons of the crack propagation trajectories.

It is worthwhile to assess whether the interfacial crack for the C30-S-225 series specimens would kink into the sandstone after propagating along the interface. Based on the previous investigations [7], there was a critical value for the ratio $K_{2}^{\mathrm{ini}} / K_{1}^{\mathrm{ini}}$ on the curve at $K_{1,2}^{*}=K_{1 \mathrm{C}}^{\mathrm{ini}}$ for the rock-concrete interfaces. When the ratio $K_{2}^{\text {ini }} / K_{1}^{\text {ini }}$ was less than the corresponding critical value, the ratio $K_{2} / K_{1}$ would always decrease as the crack propagated so that the fracture became mode I dominated. In contrast, when the ratio $K_{2}^{\mathrm{ini}} / K_{1}^{\mathrm{ini}}$ was greater than the corresponding critical value, the ratio $K_{2} / K_{1}$ would always increase as the crack propagated and the fracture became mode II dominated. According to the numerical results, the critical values of the ratio $K_{2}^{\text {ini }} / K_{1}^{\text {ini }}$ for the C50-G, C30-S and C50-S interfaces were determined as $1.22,1.34$ and 1.45 , respectively. It should be noted that although the critical ratios were different, they all corresponded to the same geometry with the rock block length of $242 \mathrm{~mm}$. In other words, the critical value of the ratio $K_{2}^{\mathrm{ini}} / K_{1}^{\mathrm{ini}}$ was determined by the stress field at the interfacial crack tip. For the composite beams with the same geometry, the same stress field could be obtained under the same loading condition. However, due to the varied properties of the materilas on the two sides of the interfaces, the calculated values of $K_{2}^{\text {ini }} / K_{1}^{\text {ini }}$ would be different. Therefore, the stress state at the interfacial crack tip, rather than the critical value of the ratio $K_{2}^{\text {ini }} / K_{1}^{\text {ini }}$, can be employed as a constant to determine the interfacial crack propagation path for a wide application. 


\section{Application of the SIF-based crack propagation criterion to the gravity dam}

In order to investigate the applicability of the criterion to practical structures, a classic example

of the Greyrock gravity dam in USA [3] was analysed in this study. The cross-sectional geometry of the dam is shown in Fig. 12. Considering the large size for this dam example, the circle mesh at the tip of the crack had a radius of $100 \mathrm{~mm}$. The first row of the elements around the crack tip had a radius of $50 / 3 \mathrm{~mm}$, and their mid-side nodes were placed at the quarter points, with a radius of $25 / 6$ $\mathrm{mm}$. Three types of loading were applied on the dam, including hydrostatic load, body forces of the dam and uplift pressure inside the crack.

The material properties used for the fracture analysis of the dam are listed in Table 5. It should

be noted that the values of the parameters $E, \rho$ and $v$ for the concrete and rock, and $K_{1 \mathrm{C}}^{\mathrm{un}}$ for the concrete, rock and their interface were quoted from literature [3]. However, the values of the initial fracture toughness $K_{1 \mathrm{C}}^{\mathrm{ini}}$ for the concrete, rock and interface would be necessary for the numerical method used in this study. Based on the experimental investigations by Dong et al. [7], the values of 
the ratio $K_{1 \mathrm{C}}^{\mathrm{ini}} / K_{1 \mathrm{C}}^{\mathrm{un}}$ for the concrete, rock and rock-concrete interface approximately ranged from 0.66 to 0.74 . Therefore, the ratio of 0.7 was adopted here for the values of $K_{1 \mathrm{C}}^{\mathrm{ini}}$ for the concrete, rock and rock-concrete interface based on the values of $K_{1 \mathrm{C}}^{\mathrm{un}}$. As a result, $0.726 \mathrm{MPa} \cdot \mathrm{m}^{1 / 2}, 0.557$ $\mathrm{MPa} \cdot \mathrm{m}^{1 / 2}$ and $0.189 \mathrm{MPa} \cdot \mathrm{m}^{1 / 2}$ were estimated for the initial fracture toughnesses of the concrete, rock and rock-concrete interface. Meanwhile, $f_{\mathrm{t}}=0.656 \mathrm{MPa}$ and $G_{\text {If }}=15.12 \mathrm{~N} / \mathrm{m}$ were also obtained

390 for the rock-concrete interface using the linear interpolation on the experimental data [7].

391 Table 5 Material parameters used in the fracture analysis of the Greyrock gravity dam.

\begin{tabular}{cccccccc}
\hline Material & $\begin{array}{c}E \\
(\mathrm{GPa})\end{array}$ & $\begin{array}{c}\rho \\
\left(\mathrm{kg} / \mathrm{m}^{3}\right)\end{array}$ & $v$ & $\begin{array}{c}f_{\mathrm{t}} \\
(\mathrm{MPa})\end{array}$ & $\begin{array}{c}K_{\mathrm{lC}}^{\text {ini }} \\
\left(\mathrm{MPa} \cdot \mathrm{m}^{1 / 2}\right)\end{array}$ & $\begin{array}{c}K_{1 \mathrm{C}}^{\text {un }} \\
\left(\mathrm{MPa} \cdot \mathrm{m}^{1 / 2}\right)\end{array}$ & $\begin{array}{c}G_{\text {If }} \\
(\mathrm{N} / \mathrm{m})\end{array}$ \\
\hline Concrete & 33.56 & 2404 & 0.255 & - & 0.726 & 1.044 & - \\
Rock & 27.25 & 0 & 0.165 & - & 0.577 & 0.802 & - \\
Interface & - & - & - & 0.656 & 0.189 & 0.273 & 15.12 \\
\hline
\end{tabular}

\subsection{Interface failure mode}

According to the practical loading conditions for the gravity dam in service, the interfacial crack could not propagation into the concrete. Therefore, only the criteria curves for the rock, i.e. $K_{\mathrm{I}, \mathrm{II}}^{*}=K_{\mathrm{Ij}}^{\mathrm{ini}}(j=$ rock $)$, and for the interface, i.e. $K_{1,2}^{*}=K_{1 \mathrm{C}}^{\mathrm{ini}}$, were compared as shown in Fig. 13. It can be seen that the curve for $K_{1,2}^{*}=K_{1 \mathrm{C}}^{\mathrm{ini}}$ was outside the curve for $K_{\mathrm{I}, \mathrm{II}}^{*}=K_{\mathrm{Ij}}^{\mathrm{ini}} \quad(j=$ rock $)$, so that the interfacial crack would always propagate along the interface.

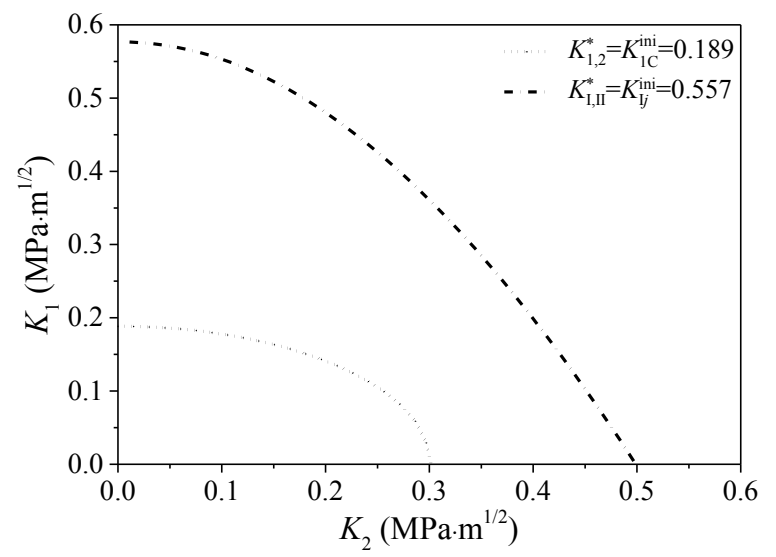


Figs. 14(a) and (b) illustrate the variations of $K_{1}$ and $K_{2}$ under various individual loading conditions, i.e. hydrostatic load (Hydro), body forces (Body) and uplifting pressures (Uplift). The

SIFs caused by the combined loading conditions, i.e. the net $K_{1}$ and $K_{2}$, were shown in these figures.

As expected, $K_{1}$ caused by the Body had a tendency to hinder the interfacial crack opening, which decreased significantly with the increase the crack length as shown in Fig. 14(a). In addition, the change rate of $K_{1}$ caused by the Body was significantly greater than those caused by the Hydro and Uplift, indicating that the effect of the Body became more prominent during the interfacial fracture process. The results agreed well with those by Kishen and Singh [3] based on the LEFM theory. In contrast, $K_{2}$ caused by the varied loads did not show obvious variation trends with the increase of the crack length, as shown in Fig. 14(b).

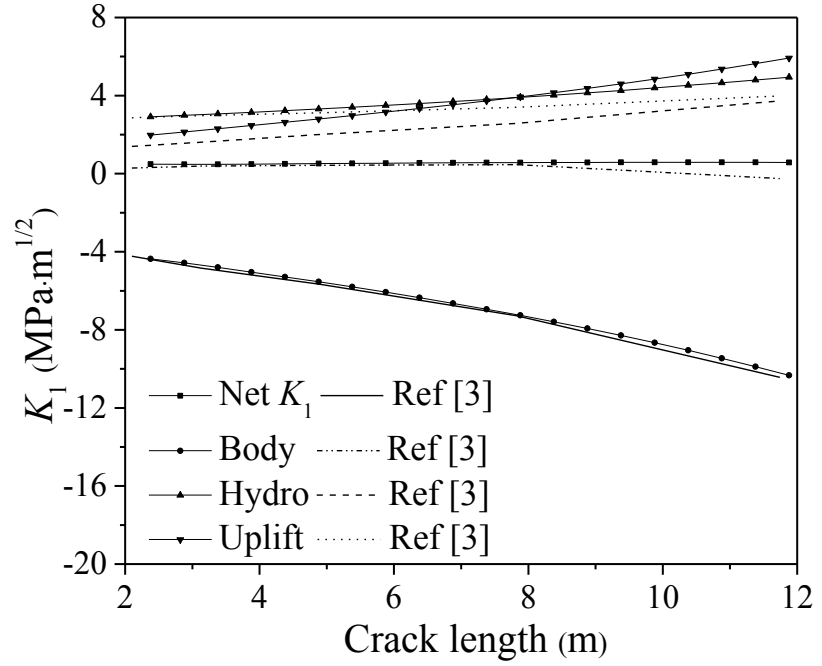

(a) $K_{1}$ versus crack length

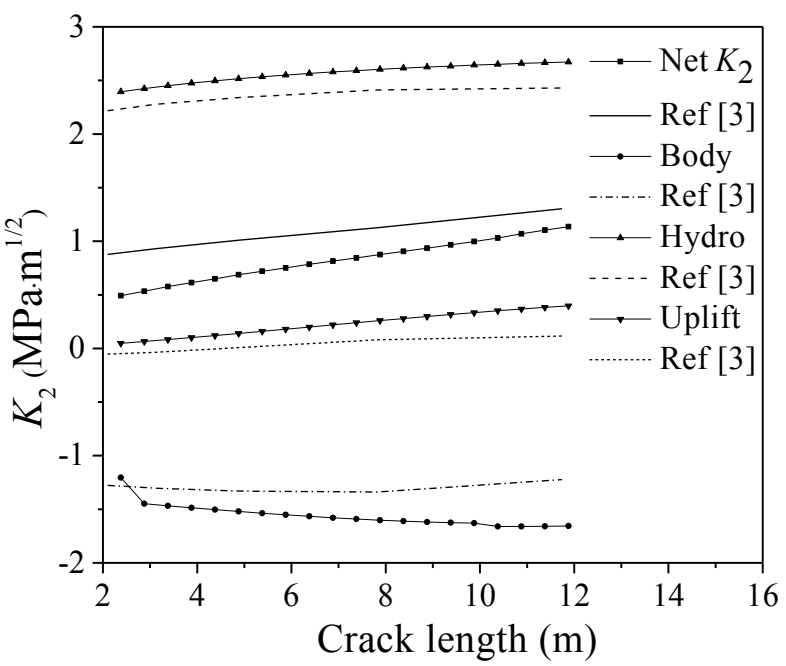

(b) $K_{2}$ versus crack length

Fig. 14. Variations of the SIFs for individual load conditions (water level of $53.289 \mathrm{~m}$ ). 
417 obviously increasing tendency, which indicated that $K_{2}$ became gradually predominant as the 418 interfacial crack propagated. However, when the water level increased from $53.289 \mathrm{~m}$ to $55.289 \mathrm{~m}$, 419 the upward tendency of $K_{2} / K_{1}$ changed to the downward trend, indicating that $K_{1}$ became more 420 prominent with the increase of the water level.

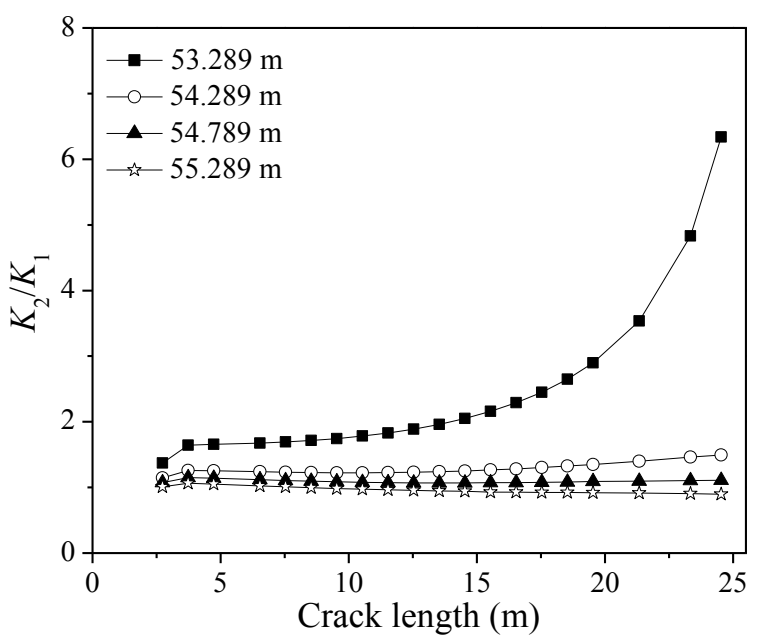

Fig. 15. Variations of $K_{2} / K_{1}$ with crack length.

In order to investigate the effects of the initial crack length and water level on the interfacial fracture behaviour, the curves of the SIFs and $K_{2} / K_{1}$ versus the water level under various initial crack lengths, i.e. $2.7 \mathrm{~m}, 3.5 \mathrm{~m}, 4.6 \mathrm{~m}$ and $6.4 \mathrm{~m}$, are illustrated in Figs. 16(a) and (b). It can be seen from Fig. 16(a) that both $K_{1}$ and $K_{2}$ increased with the increase of the water level. However, the increase of $K_{1}$ was more significant than that of $K_{2}$, indicating that the interfacial fracture tended to be mode I dominated with the increase of the water level. A similar tendency can be observed in Fig. 16(b), and the ratio $K_{2} / K_{1}$ approximately kept decreasing with the increase of the water level. Although the values of $K_{1}$ and $K_{2}$ increased with the increase of the initial crack length, the increments were not prominent. In particular, the values of the ratio $K_{2} / K_{1}$ were hardly affected by the initial crack length, as shown in Fig. 16(b).

In summary, the ratio $K_{2} / K_{1}$ was significantly affected by the water level. At the low water level, 
e.g. $53.289 \mathrm{~m}$ in this study, the ratio $K_{2} / K_{1}$ increased as the interfacial crack propagated. However, it did not vary obviously when the water level was above $54.289 \mathrm{~m}$. Meanwhile, the initial crack length had little impact on the ratio $K_{2} / K_{1}$. Thus, it could be confirmed that the interfacial crack propagation path would be different under the low water level if different concrete, rock and their interface are adopted in practical engineering.

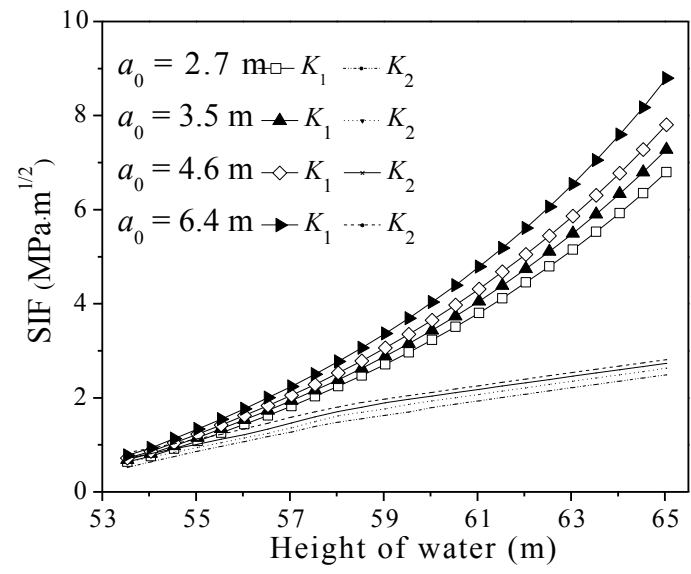

(a) SIF versus water level

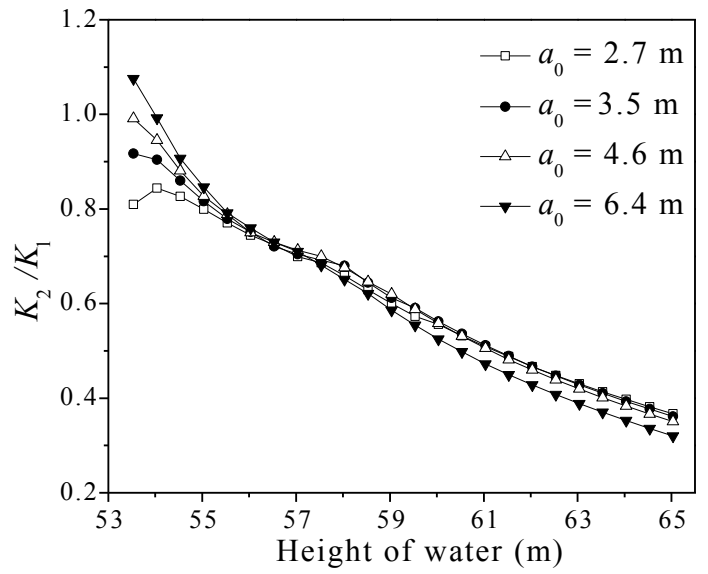

(b) $K_{2} / K_{1}$ versus water height

Fig. 16. Variations of the SIFs with water level and initial crack length.

\subsection{Kinking failure mode}

According to the experimental study [7], the initial fracture toughness of the rock-concrete interface changed approximately linearly with the roughness degree of the interface. In order to simulate different bonding conditions between the rock and concrete in practical engineering, the values of $K_{1 \mathrm{C}}^{\mathrm{ini}}$ were assumed as $0.125 \mathrm{MPa} \cdot \mathrm{m}^{1 / 2}, 0.187 \mathrm{MPa} \cdot \mathrm{m}^{1 / 2}$ and $0.350 \mathrm{MPa} \cdot \mathrm{m}^{1 / 2}$, respectively.

Meanwhile, sandstone and C30 concrete were selected in this analysis, with the corresponding material properties listed in Table 2. The fracture process was investigated for the water level of $53.289 \mathrm{~m}$, and the initial crack length was set as $2.7 \mathrm{~m}$.

Fig. 17 illustrates the $K_{1}-K_{2}$ relationships for different criteria. Accordingly, there are three 
potential crack propagation paths corresponding to different values of $K_{1 \mathrm{C}}^{\mathrm{ini}}$. When $K_{1,2}^{*}=K_{1 \mathrm{C}}^{\mathrm{ini}}=$ $0.125 \mathrm{MPa} \cdot \mathrm{m}^{1 / 2}$, the criterion curve for the interface would be inside the curve for the rock foundation, so that the crack would always propagate along the interface until failure. In contrast, when $K_{1,2}^{*}=K_{1 \mathrm{C}}^{\mathrm{ini}}=0.350 \mathrm{MPa} \cdot \mathrm{m}^{1 / 2}$, the criterion curve for the interface would be outside the curve for the rock foundation, so that the interfacial crack could kink into the rock foundation after its initiation. Finally, when $K_{1,2}^{*}=K_{1 \mathrm{C}}^{\mathrm{ini}}=0.187 \mathrm{MPa} \cdot \mathrm{m}^{1 / 2}$, there was an intersection point $\mathrm{B}$ between the criterion curves for the rock and interface, which corresponded to $K_{2} / K_{1}=1.962$. The value of $K_{2} / K_{1}$ corresponding to the crack initiation was 1.370 , which was less than 1.962 . However, according to the results shown in Fig. 17, the ratio $K_{2} / K_{1}$ would keep increasing as the interfacial crack propagated at the water level of $53.289 \mathrm{~m}$. Therefore, the interfacial crack would first propagate along the interface until the ratio $K_{2} / K_{1}$ reached 1.962 . Thereafter, the interfacial crack would kink into the rock foundation, where the predicted crack propagation length along the interface was $13.5 \mathrm{~m}$. Figs. 18(a) to (c) illustrate these three potential interfacial crack propagation paths.

To clarify the effect of the cohesive force on the interfacial fracture behaviour, a comparison of 
study.

(a) Crack always propagating along the interface

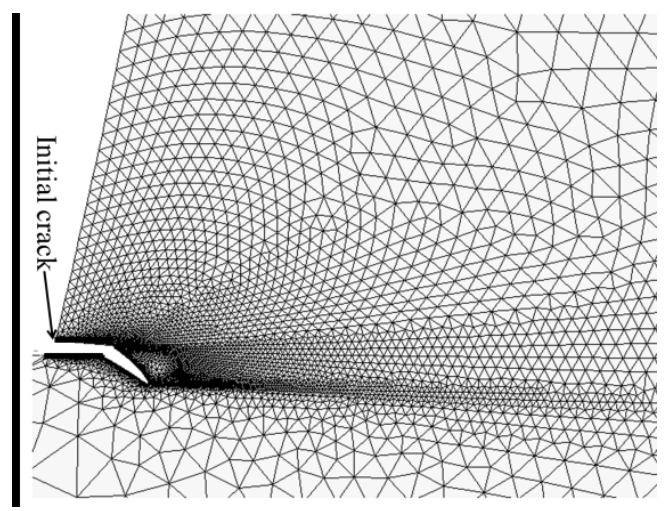

(b) Crack directly kinking into the rock foundation

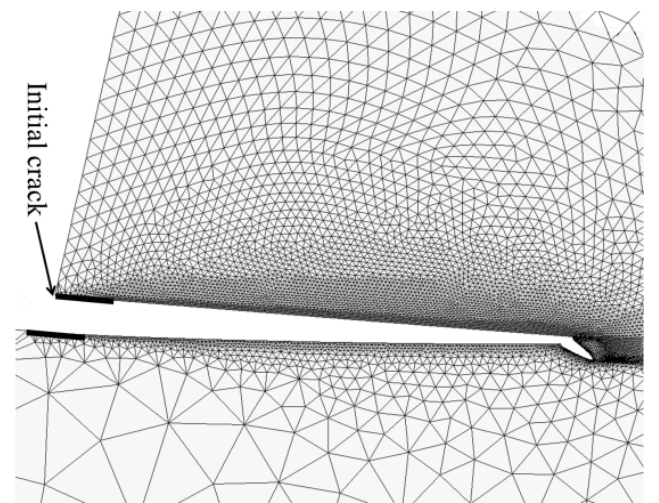

(c) Crack partly propagating along the interface and then kinking into the rock foundation

Fig. 18. Failure modes of the Greyrock gravity dam.

\subsection{Effect of the FPZ on the interfacial crack propagation of the gravity dam}

In addition, LEFM has been widely employed to determine the interfacial crack propagation path

$[3,19]$ in the rock-concrete interfacial fracture analysis. According to the size effect law [20-23], the 
fracture behaviors in a large size structure can be analyzed using the LEFM theory because the FPZ size can be negligible compared to the structure dimension. However, due to the effect of the cohesive 481 force acting on the FPZ, the stress field at the interfacial crack tip will change, leading to the variations 482 of the fracture path even for a large structure with a short FPZ length. To clarify the effect of the 483 cohesive force on the interfacial fracture behavior, a comparison of interfacial crack propagation processes with/without considering cohesive force was conducted in this study.

Fig. 19 illustrates the variations of $K_{2} / K_{1}$ with and without considering the cohesive force on the FPZ at the water level of $53.289 \mathrm{~m}$ for the Greyrock gravity dam. It can be seen that for the same crack length, the values of $K_{2} / K_{1}$ considering the cohesive force were larger than those without considering the cohesive force. Therefore, the values of $K_{2} / K_{1}$ with/without considering the cohesive 489 force would reach 1.962 with respective to the different crack propagation lengths. As a result, the 490 interfacial crack could kind into the rock foundation for the different crack propagation lengths. 491 Based on the numerical results with and without considering the cohesive force, the crack lengths 492 corresponding to kinking into the rock foundation were determined as $13.5 \mathrm{~m}$ and $15.7 \mathrm{~m}$, 493 respectively. Therefore, the interfacial crack propagation path would be predicted inaccurately if the 494 effect of the cohesive force is neglected and the LEFM method is adopted in the interfacial fracture 495 analysis. 


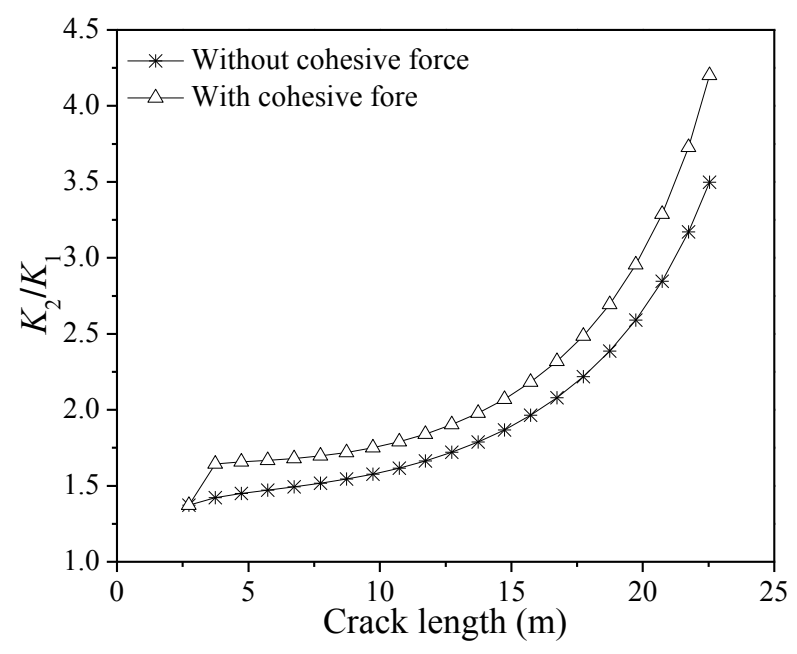

Fig. 19. Variations of $K_{2} / K_{1}$ with crack length

\subsection{Applications of different SIF-based crack propagation criteria to the gravity dam}

For the SIF-based criteria, there existed different viewpoints on the assessment of the difference between the SIFs caused by the applied load and cohesive stress. One is the mode I dominated SIF criterion, which considers that the interfacial crack would propagate when $K_{1}=K_{1 \mathrm{C}}^{\text {ini }}$ [3] (Criterion-I). The second one is the nil SIF criterion, which considers that the interfacial crack would propagate when $K_{1}=0[4,32]$ (Criterion II). The final one is the mixed mode SIF criterion, i.e. the criterion proposed in this paper (Criterion III). In summary, the expressions of these three SIF-based criteria are listed in Table 6 . It should be noted that only the crack propagation along the interface was considered in this discussion.

Table 6. Expressions of various SIF-based criteria

\begin{tabular}{cc}
\hline Interfacial criterion & Propagation condition \\
\hline I & $K_{1}=K_{1}^{\mathrm{P}}-K_{1}^{\sigma, \tau}=K_{1 \mathrm{C}}^{\mathrm{ini}}$ \\
II & $K_{1}=K_{1}^{\mathrm{P}}-K_{1}^{\sigma, \tau}=0$ \\
III & $K_{1,2}^{*}=\sqrt{\left(\frac{K_{1}^{\mathrm{P}}-K_{1}^{\sigma, \tau}}{1}\right)^{2}+\left(\frac{K_{2}^{\mathrm{P}}-K_{2}^{\sigma, \tau}}{1.6}\right)^{2}}=K_{1 \mathrm{C}}^{\mathrm{ini}}$ \\
\hline
\end{tabular}


$51153.289 \mathrm{~m}$ water level, where $K_{1 \mathrm{C}}^{\mathrm{ini}}$ was adopted as $0.189 \mathrm{MPa} \cdot \mathrm{m}^{1 / 2}$. Meanwhile, the variations of $K_{1}$

512 for three criteria with respect to the crack propagation length are also illustrated in the figure. It

513 should be noted that in the case of Criterion III, the crack propagation was dominated by the

514 combination of $K_{1}$ and $K_{2}$, so that $K_{1}$ decreased as the crack propagation. The interfacial crack would

515 not propagation when the variation curve of $K_{1}$ intersected with the criteria. Accordingly, the crack

516 propagation lengths based on the three criteria were $24.381 \mathrm{~m}, 25.564 \mathrm{~m}$ and $25.811 \mathrm{~m}$ (see Points A,

$517 \mathrm{~B}$ and $\mathrm{C}$ in Fig. 20), respectively. Because $K_{1}$ decreased to $0.0324 \mathrm{MPa} \cdot \mathrm{m}^{1 / 2}$ for Criterion III, 518 therefore, the predicted crack propagation lengths using Criteria II and III were very close.

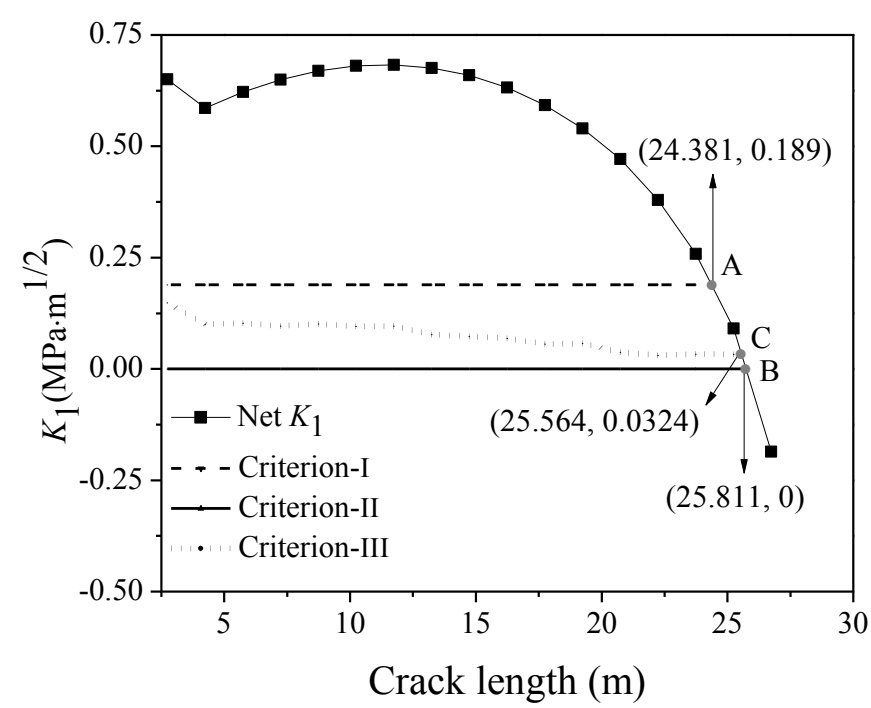

Fig. 20. Variations of $K_{1}$ with crack length at water level of $53.289 \mathrm{~m}$

Fig. 21 illustrates the relationships between the SIFs for different criteria, which can qualitatively explain the predicted results shown in Fig. 20. Points A, B and C denote the SIFS corresponding to the crack propagation under Criteria I, II and III, respectively. In the case of Criterion III, the crack propagation is dominated by the combination of mode 1 and 2 fractures. Therefore, the crack would propagate under the SIFs $K_{1}^{\text {ini }}$ and $K_{2}^{\text {ini }}$, i.e. Point C in Fig. 21. At that 
moment, due to $K_{1 \mathrm{C}}^{\mathrm{ini}}>K_{1}^{\mathrm{ini}}$, the crack would not propagate if Criterion I is employed. As a result, the interfacial cracking resistance would be overestimated under Criterion I. Particularly, the larger difference between $K_{1 \mathrm{C}}^{\mathrm{ini}}$ and $K_{1}^{\mathrm{ini}}$, the lager error would be caused. In other words, the error would increase with the increase of the ratio $K_{2}^{\text {ini }} / K_{1}^{\text {ini }}$. On the contrary, due to $K_{1}^{\text {ini }}>0$, the crack has propagated if Criterion II is used. As a result, the interfacial cracking resistance would be underestimated under Criterion I. Accordingly, the error would increase with the decrease of the ratio $K_{2}^{\mathrm{ini}} / K_{1}^{\mathrm{ini}}$

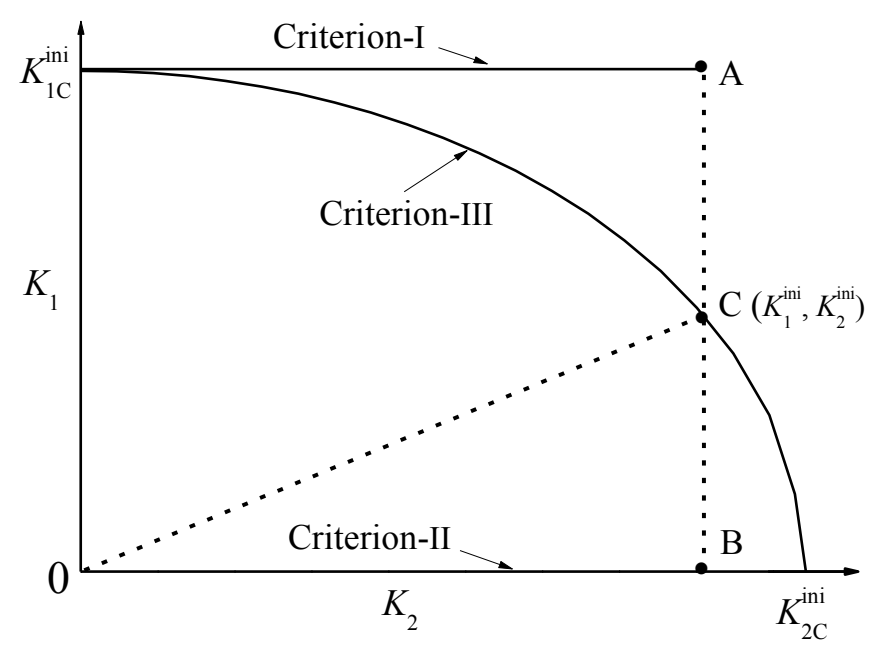

Fig. 21. Relationships of SIFs under different criteria

\section{Conclusions}

Experimental investigations were first carried out to verify the applicability of the interfacial crack propagation criterion for various categories of concrete strength and rock. The FPS tests with a wide range of mode mixity ratios were conducted on three series of rock-concrete composite beams. Thereafter, numerical analyses were accomplished to simulate the interfacial crack propagation process and predict the potential fracture paths, and validated by comparing the $P-C M O D$ curves and cracking trajectories between the experimental and numerical results. Finally, the fracture analyses on a practical gravity dam were performed numerically by applying the interfacial crack propagation 
criterion. According to the comprehensive experimental and numerical investigations, the following conclusions can be drawn:

1. The interfacial crack initiation criterion derived from the experimental studies was widely applicable to the interfaces constituted of different categories of rock and concrete with various strength grades. By combing the fictitious crack model, the crack initial criterion can be transformed into the crack propagation criterion by considering the contributions of cohesive forces on the fracture, which can be used to determine the crack propagation along the interface.

2. By assessing the relationships between the interfacial crack propagation and the maximum circumferential stress criteria for the rock and concrete, the potential interfacial crack propagation paths could be predicted. It is convenient to apply the crack propagation criterion in practical engineering because only the initial fracture toughnesses of the rock, concrete and their interface are required. Also, numerical analyses were carried out to simulate the complete interfacial fracture process by introducing these criteria, and the numerical simulations showed good agreements with the experimental results.

3. By taking a practical gravity dam as an example, the complete fracture process of the dam was analysed numerically under the actual loading conditions. Based on the relationships between these criteria, three potential propagation paths existed for the interfacial crack. The stress field at the interfacial crack tip and the initial fracture toughnesses of rock, concrete and their interface had significant effects on the interfacial crack propagation paths. If the initial fracture toughness of the rock was significantly larger than that of the interface, the interfacial crack would always propagate along the interface. If the initial fracture toughness of the rock was significantly smaller than that of the interface, the interfacial crack would kink into the rock foundation after its 
initiation. If the initial fracture toughnesses of the rock and interface were similar, the interfacial crack might first propagate along the interface and then kink into the rock foundation, which also 
Liaoning Province of China under the grant of 20170540183 are gratefully acknowledged.

\section{References}

[1] Andjelkovic V, Pavlovic N, Lazarevic Z, Nedovic V. Modelling of shear characteristics at the concrete - rock mass interface. Int J Rock Mech Min 2015;76:222-236.

[2] Bassel EI Merabi. Mechanical behavior of cohesive concrete-rock joint at the dam-foundation interface: geometrical and mechanical influence of asperities. Université Grenoble Alpes, 2018.

[3] Kishen JC, Singh KD. Stress intensity factors based fracture criteria for kinking and branching of interface crack: application to dams. Eng Fract Mech 2001;68(2):201-219.

[4] Yao F, Yang ZJ, Hu YJ. An SBFEM-based model for hydraulic fracturing in quasi-brittle materials. Acta Mech Solida Sin 2018;31(12):1-17.

[5] Slowik V, Kishen JC, Saouma VE. Mixed mode fracture of cementitious bimaterial interfaces Part I Experimental results. Eng Fract Mech 1998;60(1):83-94.

[6] Zhong H, Ooi ET, Song C, Ding T. Experimental and numerical study of the dependency of interface fracture in concrete-rock specimens on mode mixity. Eng Fract Mech 2014;124(9):287-309.

[7] Dong W, Dong Y, Zhang B. Rock-concrete interfacial crack propagation under mixed Mode I-II fracture. J Eng Mech 2018;114(6):4018039.

[8] Yuuki R. Simulation analysis of fracture in ceramic/metal bonded joints. Trans Jpn Soc Mech Eng (in Japanese) 1994;60(579):2544-2552.

[9] Tian HM, Chen WZ, Yang DS, Yang JP. Experimental and numerical analysis of the shear behaviour of cemented concrete-rock joints. Rock Mech Rock Eng 2015;48(1):213-222.

[10] Dong W, Wu Z, Zhou X. Fracture mechanisms of rock-concrete interface: experimental and numerical. J Eng Mech 2016;142(7):4016040

[11] Yang S, Song L, Li Z, Huang S. Experimental investigation on fracture toughness of interface crack for rock/concrete. Int J Mod Phys B 2008;22(31\&32):6141-6148.

[12] Yuuki R, Liu JQ, Xu JQ, Ohira T. Fracture tests and evaluation of interface crack under mixed mode condition. Trans. Jpn. Soc. Mech. Eng. (in Japanese) 1993;59(557):74-80.

[13] Ryoji Y, Liu J-Q, Xu J-Q, Toshiaki O, Tomoyoshi O. Mixed mode fracture criteria for an interface crack. Eng Fract Mech 1994;47(3):367-377.

[14] Dong W, Yang D, Zhou X, Kastiukas G. Experimental and numerical investigations on fracture process zone of rock-concrete interface. Fatigue Fract Eng M 2017;40(5):820-835.

[15] Červenka J, Kishen JC, Saouma VE. Mixed mode fracture of cementitious bimaterial interfaces Part II Numerical simulation. Eng Fract Mech 1998;60(1):95-107.

[16] Sujatha V, Kishen JC. Energy release rate due to friction at bimaterial interface in dams. J Eng Mech 2003;129(7): 793-800.

[17] Datta D, Tomar V, Varma AH. A path independent energy integral approach for analytical fracture strength of steel-concrete structures with an account of interface effects. Eng Fract Mech 2018;204:246-267.

[18] Benarbia D, Benguediab M. Determination of stress intensity factor in concrete material under Brazilian disc and three-point bending tests using finite element method. Periodica Polytechnica. Engineering. Mech Eng 2015:59(4),199-203. 
[19] Yang Z, Xu FX. A heterogeneous cohesive model for quasi-brittle materials considering spatially varying random fracture properties. Comput Methods Appl Mech Eng 2008;197:4027-4039.

[20] Bažant ZP, Pfeiffer PA. Determination of fracture energy from size effect and brittleness number. ACI Mater J 1987;84(6):463-480.

[21] Bažant ZP, Kazemi M T. Size effect in fracture of ceramics and its use to determine fracture energy and effective process zone length. J Am Ceram Soc 1990;73(7):1841-1853.

[22] Bažant ZP, Planas J. Fracture and Size Effect in Concrete and Other Quasibrittle Materials. CRC Press 1997.

[23] Bažant ZP, Yu Q. Universal size effect law and effect of crack depth on quasi-brittle structure strength. J Eng Mech 2009;135(2):78-84.

[24] Yang ZJ, Li BB and Wu JY. X-ray computed tomography images based phase-field modeling of mesoscopic failure in concrete, Eng Fract Mech 2019;208:151-170.

[25] Huang YJ, Yang ZJ, Ren WY, Liu GH and Zhang C. 3D Meso-scale fracture modelling and validation of concrete based on in-situ X-ray computed tomography images using damage plasticity model, Int J Solids Struct 2015;67-68:340-352.

[26] Su XT, Yang ZJ and Liu GH. Monte Carlo simulation of complex cohesive fracture in random heterogeneous quasi-brittle materials: a 3D study. Int J Solids Struct 2010;47:2336-2345.

[27] Nagashima T, Omoto Y, Tani S. Stress intensity factor analysis of interface cracks using X-FEM. Int J Numer Meth Eng 2003;56(8):1151-1173.

[28] Wu ZM, Rong H, Zheng JJ, Dong W. Numerical method for mixed mode I-II crack propagation in concrete. J Eng Mech 2013;139(11):1530-1538.

[29] Yuuki R, Xu J-Q. Stress based criterion for an interface crack kinking out of the interface in dissimilar materials. Eng Fract Mech 1992;41(5):635-644.

[30] Hillerborg A, Modéer M, Petersson P. Analysis of crack formation and crack growth in concrete by means of fracture mechanics and finite elements. Cement Concrete Res 1976;6(6):773-781.

[31] Yang Z, Propagation MC, Procedure R. Fully automatic modelling of mixed-mode crack propagation using scaled boundary finite element method. Eng Fract Mech 2006;73(12):1711-1731.

[32] Moës N, Belytschko T. Extended finite element method for cohesive crack growth. Eng Fract Mech 2002;69(7):813-833. 